Structurally integrated photoluminescence-based lactate sensor using organic light emitting devices (OLEDs) as the light source

by

\title{
Chengliang Qian
}

\author{
A thesis submitted to the graduate faculty \\ in partial fulfillment of the requirements for the degree of \\ MASTER OF SCIENCE \\ Major: Condensed Matter Physics \\ Program of Study Committee: \\ Joseph Shinar, Major Professor \\ Rana Biswas \\ Charles Kerton \\ Vikram Dalal
}

Iowa State University

Ames, Iowa

2006

Copyright (C) Chengliang Qian, 2006. All rights reserved. 


\section{Graduate College \\ Iowa State University}

This is to certify that the master's thesis of

\section{Chengliang Qian}

has met the thesis requirements of Iowa State University

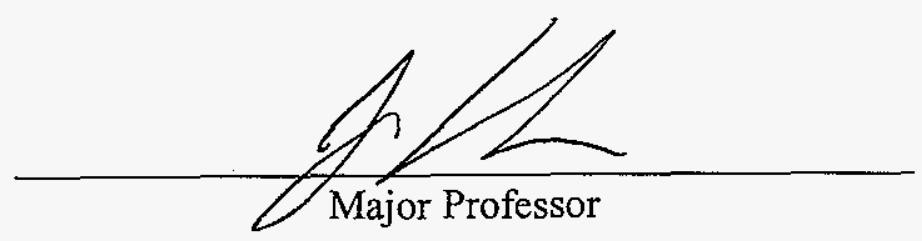

For the Major Program 


\section{TABLE OF CONTENTS}

LIST OF ABBREVIATIONS $\ldots \ldots \ldots \ldots \ldots \ldots \ldots \ldots \ldots \ldots \ldots \ldots \ldots \ldots \ldots \ldots \ldots$

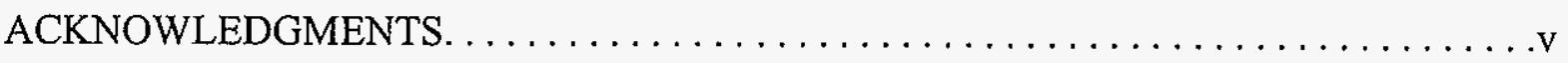

ABSTRACT $\ldots \ldots \ldots \ldots \ldots \ldots \ldots \ldots \ldots \ldots \ldots \ldots \ldots \ldots \ldots \ldots \ldots \ldots \ldots$

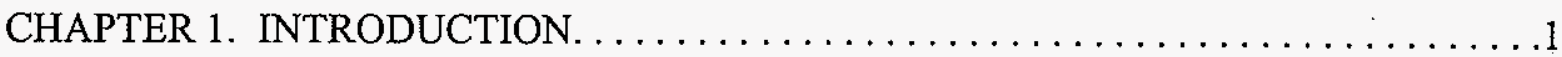

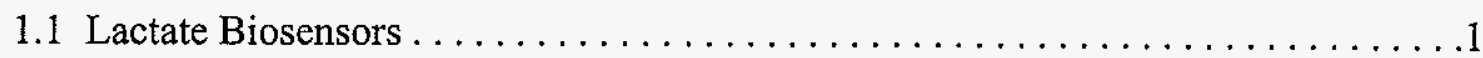

1.2 Organic Light Emitting Devices (OLEDs) $\ldots \ldots \ldots \ldots \ldots \ldots \ldots \ldots \ldots$

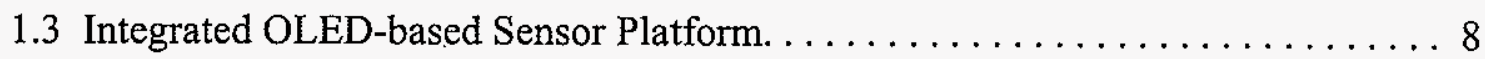

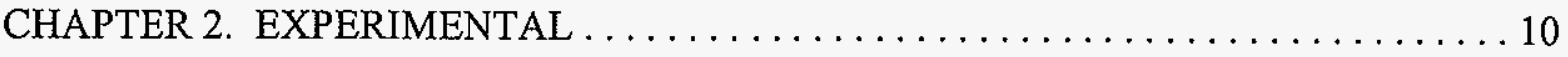

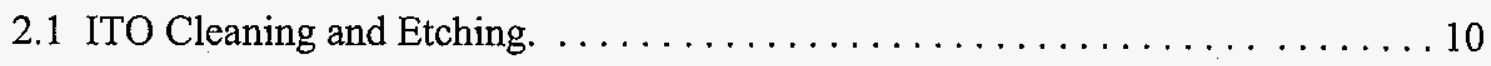

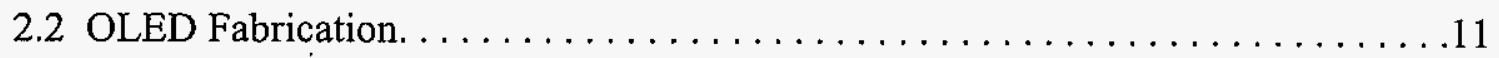

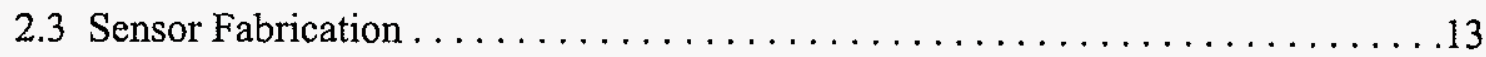

2.3 .1 Reagents. . . . . . . . . . . . . . . . . . . . .

2.3.2 Film/solution sensing component $\ldots \ldots \ldots \ldots \ldots \ldots \ldots \ldots \ldots \ldots$

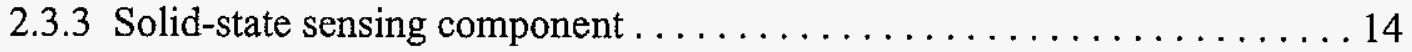

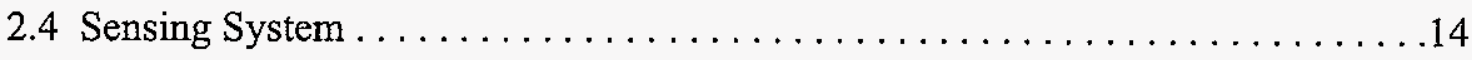

CHAPTER 3. RESULTS AND DISCUSSIONS $\ldots \ldots \ldots \ldots \ldots \ldots \ldots \ldots \ldots \ldots$

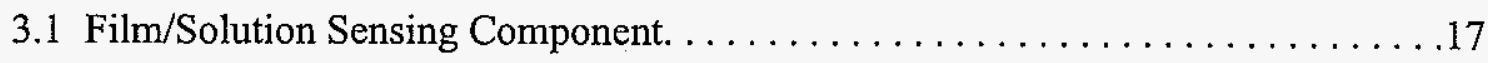

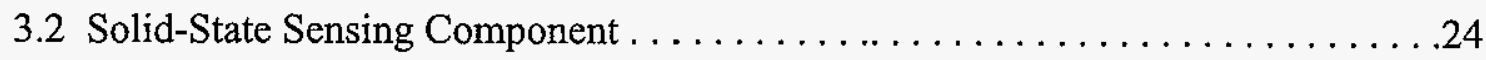

CHAPTER 4. MULTIANALYTE SENSING ARRAY $\ldots \ldots \ldots \ldots \ldots \ldots \ldots \ldots$

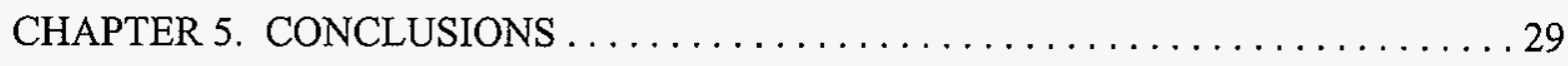

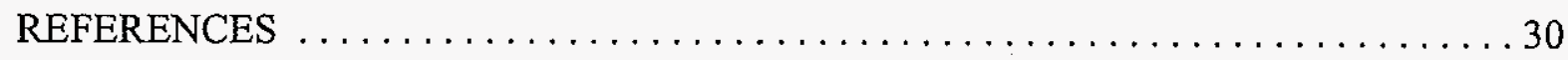




\section{LIST OF ABBREVIATIONS}

$\mathrm{Alq}_{3}$ : tris-(8-hydroxyquinoline) aluminum

CsF: cesium fluoride

CuPc: copper phthalocyanine

DO: dissolved oxygen

EL: electroluminescence

ETL: electron transport layer

HOMO: highest occupied molecular orbital

HTL: hole transport layer

$I$ : intensity of photoluminescence

ITO : Indium-Tin-Oxide

LOx: lactate oxidase

LUMO: lowest unoccupied molecular orbital

$\mathrm{mM}$ : milimolar

MTEOS: methyltriethoxysilane

NPD: N, N'-diphenyl-N,N'-bis(1-naphthylphenyl)-1,1'-biphenyl-4,4'-diamine

OLEDs: organic light emitting devices

PEI: polyethyleneimine

PL: photoluminescence

PMT: photo multiplier tube

PS: polystyrene

PtOEP: Platinum octaethyl porphyrin

$R$ : molar water/precursor ratio

SE: singlet exciton

$\tau$ : lifetime of photoluminescence

TE: triplet exciton

TEOS: tetraethoxysilane

TMOS: tetramethoxysilane 


\section{ACKNOWLEDGEMENTS}

I am grateful to my advisor, Professor Joseph Shinar, who supervised me over the last two years and constantly encouraged me and helped me throughout my entire graduate study. My special thanks go to Dr. Ruth Shinar for her helpful instruction on my research. Without their guidance and support, this work would not have been done.

I greatly thank Yuankun Cai, Zhaoqun Zhou and Bhaskar Choudhury for their generous help with my experiments. I also benefited a lot from the warm discussions with them.

I would like to thank Dr. Rana Biswas, Dr. Charles Kerton and Dr. Vikram Dalal for being on my graduate committee. I appreciate their time and valuable comments on my thesis.

Finally, I am deeply indebted to my parents who have always been supporting me in my life and in my study.

This work was performed at Ames Laboratory under Contract No. W-7405-Eng-82 with the U.S. Department of Energy. The United States government has assigned the DOE Report number IS-T 2636 to this thesis. 


\begin{abstract}
Multianalyte bio(chemical) sensors are extensively researched for monitoring analytes in complex systems, such as blood serum. As a step towards developing such multianalyte sensors, we studied a novel, structurally integrated, organic light emitting device (OLED)based sensing platform for detection of lactate. Lactate biosensors have attracted numerous research efforts, due to their wide applications in clinical diagnosis, athletic training and food industry. The OLED-based sensor is based on monitoring the oxidation reaction of lactate, which is catalyzed by the lactate oxidase (LOx) enzyme. The sensing component is based on an oxygen-sensitive dye, Platimum octaethyl porphyrin (PtOEP), whose photoluminescence (PL) lifetime $\tau$ decreases as the oxygen level increases. The PtOEP dye was embedded in a thin film polystyrene (PS) matrix; the LOx was dissolved in solution or immobilized in a solgel matrix. $\tau$ was measured as a function of the lactate concentration; as the lactate concentration increases, $\tau$ increases due to increased oxygen consumption. The sensors' performance is discussed in terms of the detection sensitivity, dynamic range, and response time. A response time of $\sim 32 \mathrm{sec}$ was achieved when the LOx was dissolved in solution and kept in a closed cell. Steps towards development of a multianalyte sensor array using an array of individually addressable OLED pixels were also presented.
\end{abstract}




\section{CHAPTER 1. INTRODUCTION}

\subsection{Lactate Biosensors}

Over the last three decades, the monitoring of lactate has attracted increasing research interest. Lactate is one of the principal products of anaerobic metabolism in living organisms and some bacteria $[1,2]$, so that it is of great importance in monitoring athletic training, medical care and food industry. The determination of blood lactate is also critical for the diagnosis of many diseases, like stroke [3] and liver failure [4]. The normal lactate level in human blood is $0.5 \sim 2.2 \mathrm{mM}$ [5]. An elevated level of blood lactate (>3.0 mM) may indicate some fatal diseases [4]. In food industry, fermentation or preservation requires accurate lactate monitoring $[6,7]$.

Different methods have been explored to determine lactate level in different samples in vivo or in vitro. Lactate oxidase (LOx) has emerged as an important lactate recognition element, due to its high selectivity for lactate and ease of coupling with amperometric and optical transducers $[8 \sim 10]$. Lactate is determined by its oxidation to pyruvate in the presence of LOx. The reaction is:

$$
\text { Lactate }+\mathrm{O}_{2}=\text { Pyruvate }+\mathrm{H}_{2} \mathrm{O}_{2}
$$

For amperometric lactate biosensors, the electrode can act as a Clark-type oxygen electrode that detects the oxygen [11, 12]; alternatively the amount of the peroxide produced can be measured [13 17]. However, the Clark-type oxygen electrodes suffer from a longterm current drift due to their high dependence on the diffusion properties of electrode membrane and the conductivity of electrolyte solution [18]; amperometric lactate sensors require a long pre-treatment time of electrodes ( 20min) [16] and exhibit a long response time of $\sim 5 \mathrm{~min}[13]$.

Optical enzyme-based biosensors, including fiber-optic biosensors, have been studied extensively [19]. Monitoring luminescence quenching is one of the commonly employed methods [10]. For lactate detection, an oxygen-sensitive dye can be used to monitor the $\mathrm{O}_{2}$ level, which is affected by the concentration of lactate (see Equ.1). Both the photoluminescence (PL) intensity $I$ and lifetime $\tau$ of the dye decrease as the oxygen (the 
quencher) concentration increases. The luminescence quenching obeys Stern-Volmer relation:

$$
I_{0} / I=\tau_{0} / \tau=1+K_{S V}\left[O_{2}\right]
$$

where $I_{0}$ and $\tau_{0}$ are the luminescence intensity and lifetime in the absence of $\mathrm{O}_{2}$, respectively; $I$ and $\tau$ are the luminescence intensity and lifetime in the presence of $\mathrm{O}_{2}$, respectively. $\mathrm{K}_{S V}$ is the Stern-Volmer constant and $\left[\mathrm{O}_{2}\right]$ is the $\mathrm{O}_{2}$ concentration.

Various fiber-optic biosensors based on PL quenching of ruthenium organic complexes have been studied [20 23]. Platinum octaethyl porphyrin (PtOEP) can also be employed as a PL-quenching indicator [24]. PtOEP offers good absorption in visible region, a large stoke shift and good photostability [25]. It also has a longer $\tau$ of $\sim 100 \mu$ s in the absence of oxygen in comparison to ruthenium complexes $(\sim 10 \mu \mathrm{s})$ [26], so that PtOEP exhibits higher sensitivity. In this work, we employed PtOEP as the sensing dye.

A PL-based biosensor requires several basic components, including a luminescing sensing element that probes the analyte, a light source that excites the sensing element, and a photodetector or photospectrometer that receives the signals [27, 28]. Often, PL-based optical biosensors employ bulky and high power light sources, such as lasers [29, 30], halogen lamps [20], or xenon lamps [21, 23]. However, the need for miniaturized and integrated sensing system is growing [31,32]. In the past few years, our group has utilized thin-film organic light emitting devices (OLEDs), which can be easily integrated with the thin-film sensing component $[26,27]$. This approach results in a compact and highly integrated sensing platform for various chemical or biological analytes, including oxygen [33], hydrazine, anthrax [34], and glucose [26].

Recently, immobilization of enzymes in sol-gel silicate glasses for chemical or biochemical sensor applications has attracted considerable research $[35,36]$. Compared with many other methods of immobilization, e.g., adsorption of enzymes onto a substrate, covalent bonding and entrapment of enzymes within a polymeric matrix, the sol-gel process offers several advantages, such as good enzyme caging, compatibility with many organic reagents and enzymes, optical transparency, thermal and chemical stability, and room temperature processing with controllable pore size and surface area [37].

In contrast, adsorption suffers from a strong enzyme leaching [38]; covalent binding tends to result in a reduced sensor response due to the reduced degree of freedom of the 
bonded enzymes [39]; a polymeric matrix is often thermally and mechanically unstable [40].

A typical sol-gel process is shown in Fig.1.1 [41]. It involves the following steps:

1) Hydrolysis: The precursor, e.g., tetramethoxysilane (TMOS) or tetraethoxysilane (TEOS), is hydrolyzed by water under acidic catalysis. Silanol groups (Si-OH) and ethanol (or methanol) are formed.

2) Condensation: Silanol moieties react to form siloxane groups (Si-O-Si). Ethanol (or methanol) and water are produced.

3) Polymerization: Siloxane groups react with each other and form long-chain polymers; the solvents are evaporated and pores are formed upon drying.

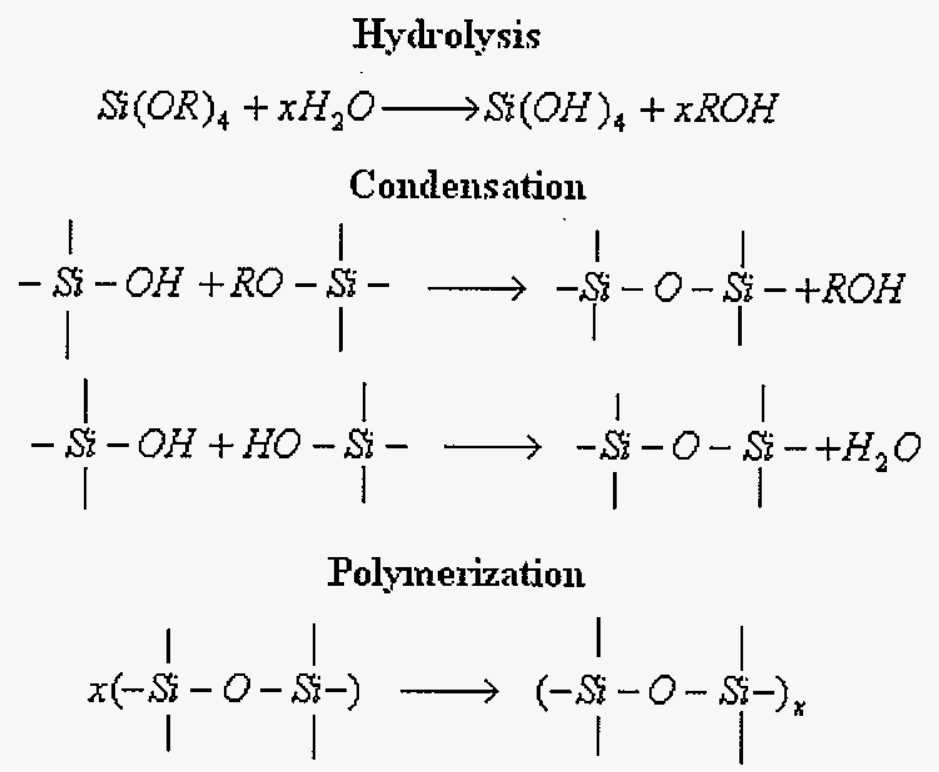

Fig.1.1: Three steps of sol-gel process. $\mathrm{R}$ represents a group such as $-\mathrm{CH}_{3}$ or $-\mathrm{CH}_{2} \mathrm{CH}_{3}$.

One important parameter for sol-gel film tailoring is the molar water/precursor ratio $R$. As $R$ increases, the pore size decreases, the drying time (at a given temperature) shortens, and the sensor sensitivity is reduced [42].

The properties of TEOS-based sol-gel films can also be tailored by adding organically modified precursors, e.g., methyltriethoxysilane (MTEOS).

Issues associated with enzyme immobilization in sol-gel include: 
1) Narrow-pore gel network limits the reaction rate, because of the limited accessibility of analyte to the enzyme's active site [37].

2) Enzymes (e.g., LOx) often lose most of their initial activity after immobilization in a sol-gel matrix [43 45]. The situation is caused by

a) leaching of enzymes from the sol-gel porous network $[39,46]$;

b) deactivation of the enzymes due to electrostatic interactions between critical enzyme surface sites and countercharged sites of the rigid matrix [47], or due to ethanol/methanol produced during the sol-gel process and low $\mathrm{pH}$ values $[41,48,49]$.

In the past decade, approaches to overcome these issues were developed. Wolfbeis et al found that the addition of sorbitol resulted in more porous sol-gel matrix, which enhanced the activity of the enzyme [23]. Cox et al proposed the addition of polyethyleneimine (PEI) as the LOx sheathing that overcame the electrostatic interactions between the enzyme and the matrix [50]. In order to minimize the detrimental effect of alcohol generated during the hydrolysis step, a novel alcohol-free method was proposed, where a vacuum was used to enhance alcohol evaporation before mixing the sol and the enzyme [43, 51]. The acidic sol (which is preferred for the hydrolysis) can also be adjusted to reach a neutral $\mathrm{pH}$ value by adding buffer solution ( $\mathrm{pH}$ 7.4), in order to accommodate the enzyme properly [43]. And the quick rise in $\mathrm{pH}$ increased the sol condensation rate, resulting in quick gelation [44]. Additionally, the incorporation of organosilanes (MTEOS) as a sol precursor can remarkably reduce the extent of enzyme leaching [46].

\subsection{Organic Light Emitting Devices (OLEDs)}

OLEDs are developing rapidly, since Tang's and Van Slyke's 1987 groundbreaking report [52] on high-efficiency, high-brightness, and low voltage $(<10$ volts $)$ thin film OLEDs. The efficiency and stability of OLEDs have dramatically improved over the past decade [53,54]. External quantum efficiency of $18 \%$ has been achieved for green OLEDs [55]. The operational lifetime of green OLEDs has also been extended to $4000 \mathrm{hr}$ at a brightness of $510 \mathrm{~cd} / \mathrm{m}^{2}$ [56]. 
There are generally two types of OLEDs: small molecule and polymer. In this work, the OLEDs were fabricated by using small molecular $\pi$-conjugated materials, e.g., tris-(8hydroxyquinoline) aluminum ( $\left.\mathrm{Alq}_{3}\right)$. In $\pi$-conjugated materials, single and double or single and triple bonds alternate throughout the backbone of the molecule. The second and third bonds of a double or triple bond are $\pi$ bonds [57]. The $\pi$ (bonding) orbitals form a delocalized valence band termed highest occupied molecular orbital (HOMO) and the $\pi^{*}$ (antibonding) orbitals form a delocalized conduction band termed lowest unoccupied molecular orbital (LUMO). Both of the bands support mobile charge carriers [53]. The gap between the LUMO and HOMO is typically in the $1.5 \sim 3 \mathrm{eV}$ range, i.e. the materials are organic semiconductors [57].

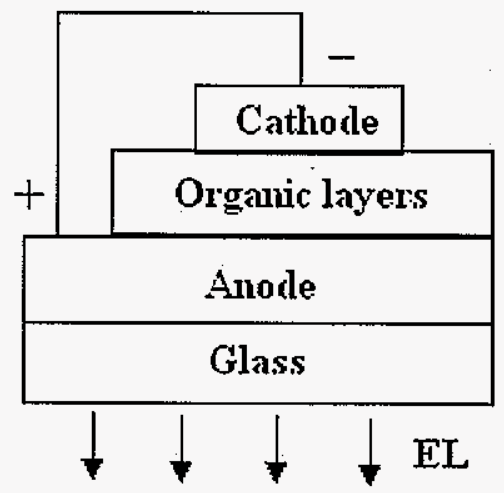

Fig.1.2: Basic Configuration of an OLED

A typical OLED consists of organic layers sandwiched between the anode and cathode (see Fig.1.2). When the external bias $V=0$, the Fermi levels of cathode and anode are aligned and no current flows through the device (see Fig.1.3a). Once a bias $V_{a p p}$ is applied, electrons and holes are injected and drift toward to the emission layer under the external electrical field. The electrons and holes typically need to overcome electron injection barrier and hole injection barrier, respectively (see Fig.1.3b). 


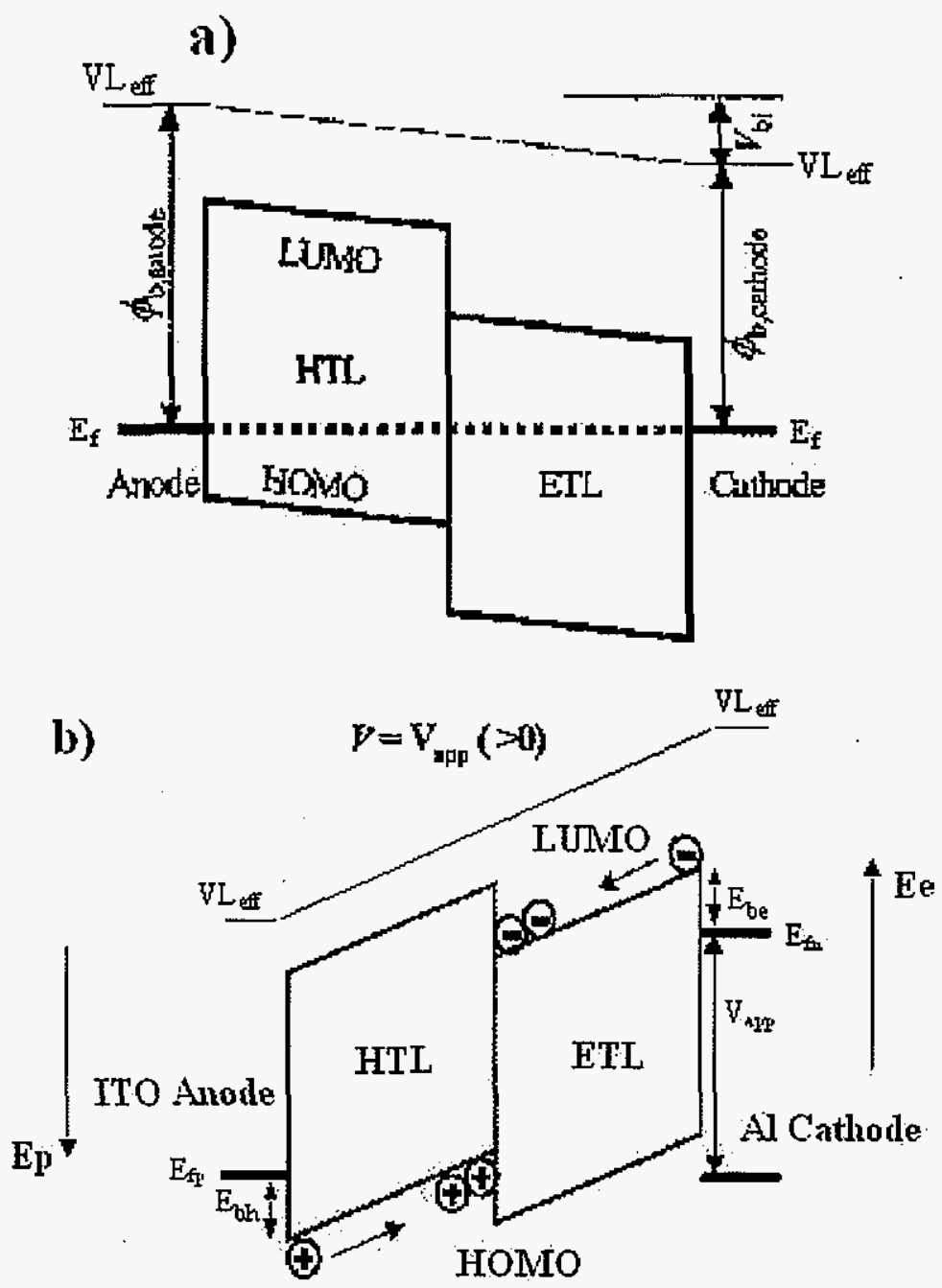

Fig.1.3: Band diagram of an OLED device a) without a bias and b) with a bias $V_{a p p}$. VL eff is the effective vacuum level; $\Phi_{\text {anode }}$ is the work function of anode; $\Phi_{\text {cathode }}$ is the work function of cathode; $V_{b i}$ is the built-in voltage; $E_{f}$ is the equilibrium Fermi level; $E_{\mathrm{fh}}$ is the quasi hole Fermi level; $E_{f n}$ is the quasi electron Fermi level; $E_{b h}$ is the hole injection barrier; $E_{b e}$ is the electron injection barrier [58].

The injected electrons and holes drift until they recombine and form bound excited states named excitons. A spin 1/2 hole and a spin $1 / 2$ electron can form either one singlet exciton (SE with spin $S=0$ ) or three triplet excitons (TE with $S=1$ ). In most stable molecules, the HOMO is completely filled in the ground state and the ground state wavefunctions are spatially symmetric and spin-antisymmetric under electron exchange [59], so that the ground 
state is singlet. According to the rule of spin conservation, the decay of SEs is allowed ( $\tau_{\text {fluorescence }} \sim$ a few ns), but the decay of TEs is prohibited. Therefore, the light emission of OLEDs is mainly due to the radiative SE decay, which is called fluorescence. Although triplet-to-singlet decay is forbidden, certain second order effects (e.g., intersystem crossing) may mix singlet and triplet states, making the triplet decay weakly allowed (so $0.1<$ $\tau_{\text {phosphorsecence }}<10^{6} \mu \mathrm{s}$ ), which is known as phosphorescence [59].

In order to improve the electroluminescence (EL) efficiency, it is important to obtain high brightness at low driving voltage. The mobility of both holes and electrons is much lower in organic semiconductors compared with inorganic semiconductors $[60,61]$. Reducing the thickness of the organic layers can help lower the driving voltage, but causes pinholes in the film that are detrimental to OLEDs. A multilayered structure is therefore essential to the performance of OLEDs [62].

Generally, an OLED consists of five layers. They are the anode, hole transport layer (HTL), emission layer, electron transport layer (ETL) and cathode. It can be seen from Fig.1.3b that a high anode work function is desired in order to lower the hole injection barrier and a low cathode work function is needed to reduce the electron injection barrier. The HTL acts as a p-layer that enhances hole transport and blocks the leakage of electrons to the anode. The ETL enhances electron transport and blocks the leakage of holes to the cathode. Therefore, both carriers can be confined to the emission layer and to form excitons that decay radiatively.
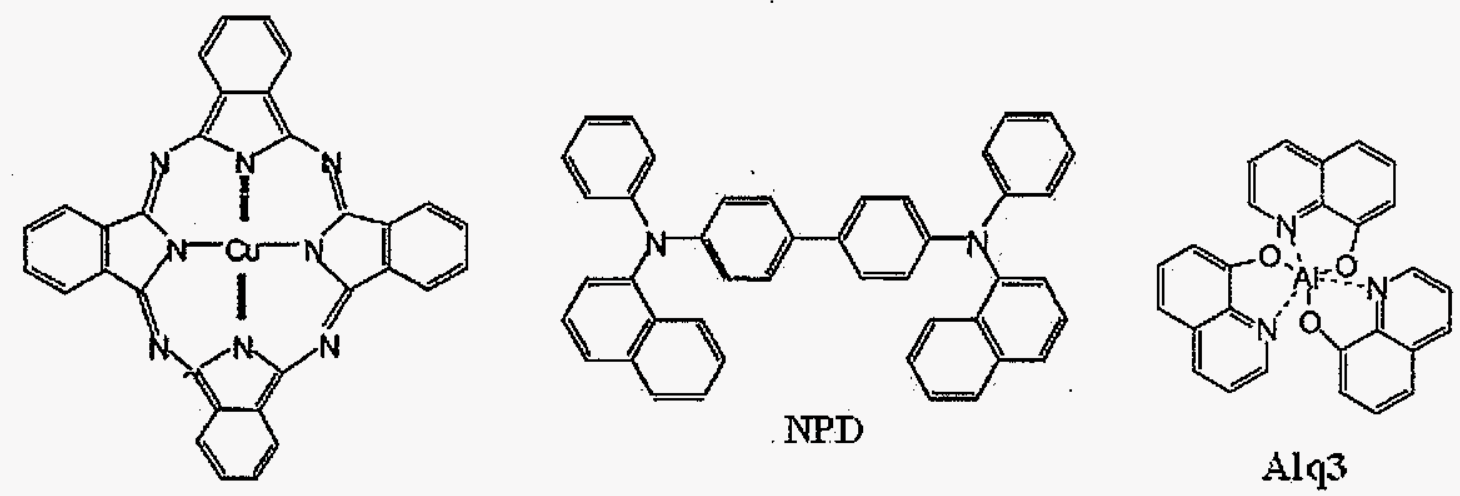

$\mathrm{CuPc}$

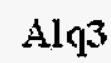

Fig.1.4: Molecular structures of the organic materials. 
Indium-Tin-Oxide (ITO), a transparent conducting oxide, is one of the most common anode materials for OLEDs. Small molecule OLEDs are usually deposited on ITO coated glass substrates. Its work function is typically $\sim 4.5 \mathrm{eV}$ and increases with the oxygen content up to $\sim 5.1 \mathrm{eV}$. Since higher ITO work function is desired for higher device brightness and efficiency, the ITO surface is pre-treated by exposing it to UV illumination, which generates ozone that removes contaminants from the ITO surface and saturates it with oxygen [63].

Copper Phthalocyanine ( $\mathrm{CuPc}$ ) is widely used as an HTL or a hole injection buffer layer. It is usually inserted between the anode and the HTL. Since its work function is $0.1 \sim 0.2 \mathrm{eV}$ higher than that of ITO, it can enhance the hole injection [64].

$\mathrm{N}, \quad \mathrm{N}^{\prime}$-diphenyl-N,N'-bis(1-naphthylphenyl)-1,1'-biphenyl-4,4'-diamine (NPD) is commonly used as an HTL. NPD significantly enhances the stability of the OLEDs, due to its high glass transition temperature $\left(\sim 95^{\circ} \mathrm{C}\right)[57]$.

$\mathrm{Alq}_{3}$ is a green emitter that has attracted more interest than any other small molecular emitter materials $[52,65,66] . \mathrm{Alq}_{3}$ acts both as electron transport layer and emission layer in green OLEDs.

Cesium Fluoride $(\mathrm{CsF})$ is used as an electron buffer layer. It is inserted between the ETL and the cathode (e.g., between the $\mathrm{Alq}_{3}$ and the $\mathrm{Al}$ ). $\mathrm{CsF}$ results in the formation of a dipole charge layer, which lowers the barrier for electron injection [67].

$\mathrm{Al}(\Phi=4.3 \mathrm{eV})$ or $\mathrm{Ca}(\Phi=2.87 \mathrm{eV})$ is commonly used as the cathode material.

\subsection{Integrated OLED-based Sensor Platform}

OLEDs and sensing components are easily structurally integrated by fabricating the OLED and the sensing component on separate glass substrates that are attached back-toback. As such, the thickness of the OLED/sensor-component module is determined by that of the glass substrates. The sensor was operated in a "back-detection" geometry, shown in Fig.1.5, where the photodetector is located behind the OLED, collecting the PL in the gaps between the OLED pixels. 


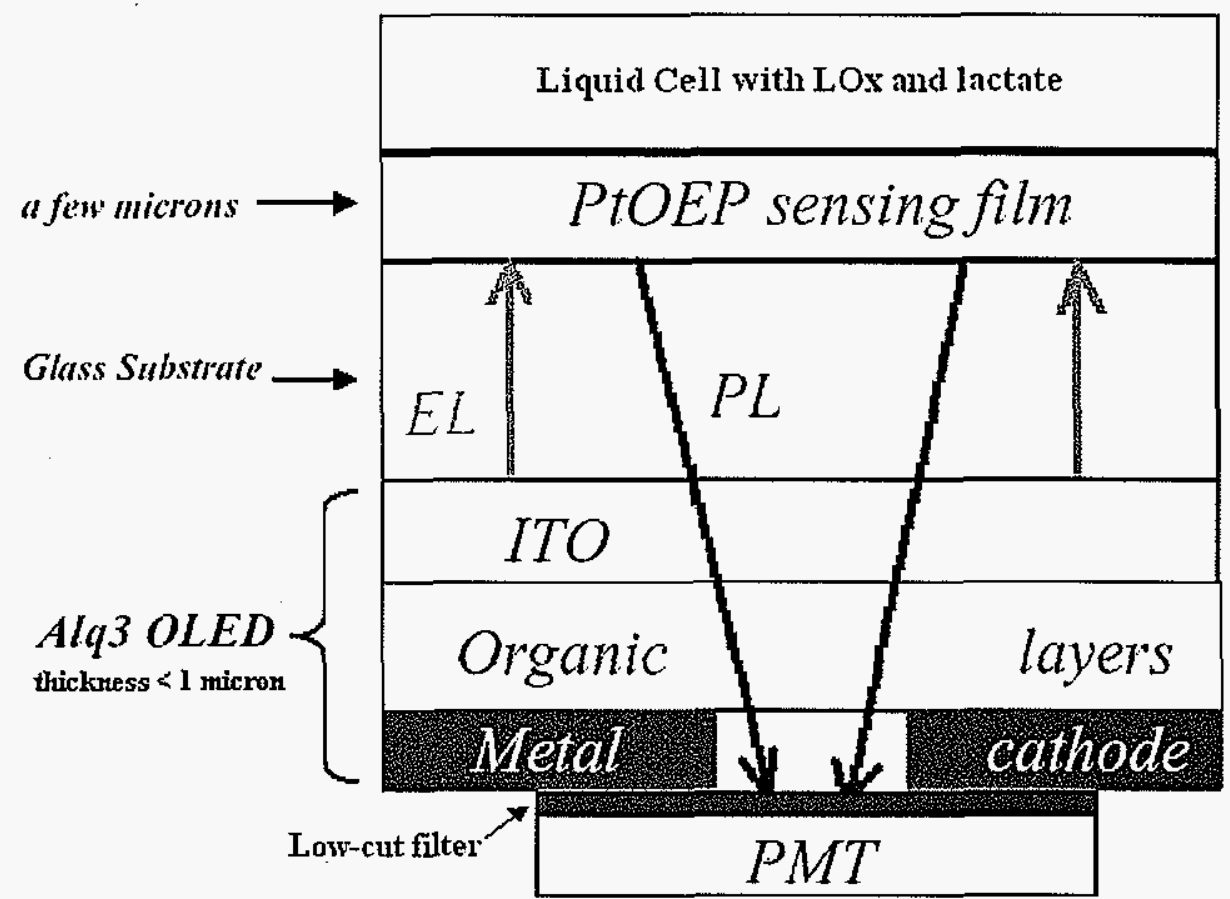

Fig.1.5: Schematic of "back detection" mode [26]

In this work, we report a structurally integrated OLED-based lactate sensor designed towards the development of a multianalyte sensing array. A sensing component was integrated with low-power, thin-layered green $\mathrm{Alq}_{3}$ OLEDs as the light source [27]. The advantages of OLED-excited sensors include their compact size, ease of fabrication, simple structure, and low cost. OLEDs can easily be integrated with sensing films and thin-film photodetectors [68], which provides a promising sensing platform for multianalyte detection. We used PtOEP embedded in polystyrene (PS) as the sensing component. It was termed as "film/solution sensing component" when the LOx was in solution or termed as "solid-state sensing component" when the LOx was immobilized in sol-gel matrix. The effect of the enzyme concentration and the sensing film configuration on the sensor sensitivity, dynamic range and response time was evaluated. Additionally, the potential use of the lactate sensor in a multianalyte sensing array using individually addressable OLED pixels was presented. 


\section{CHAPTER 2. EXPERIMENTAL}

\subsection{ITO Cleaning and Etching}

The OLED fabrication began with careful cleaning of the ITO coated glasses. In this work, $20 \Omega /$ sq ITO-coated glass substrates (Applied Films Corp.) were used. The cleaning procedure was as follows [69]:

1) Prepare ITO surfactant with $30 \mathrm{ml}$ RBS-35 Detergent Concentrate (from PIERCE) in $1000 \mathrm{ml}$ deionized water and $400 \mathrm{ml}$ isopropanol.

2) Submerge ITO substrates into the surfactant and ultra-sonicate for $\sim 15 \mathrm{~min}$.

3) Wash ITO substrates in flowing distilled water for $\sim 15 \mathrm{~min}$.

4) Submerge ITO substrates into isopropanol for $2 \sim 3 \mathrm{~min}$.

5) Drain out isopropanol, submerge ITO substrates into acetone and ultra-sonicate for $3 \sim 5 \mathrm{~min}$.

6) Remove acetone, submerge ITO substrates into isopropanol for $2 \sim 3 \mathrm{~min}$.

7) Blow dry with argon.

8) Mark non-ITO side.

9) Attach firmly two strips of black tape to the ITO side. Each strip is 2-mm wide and there is a $1-\mathrm{mm}$ separation in between the two strips.

10) Submerge the ITO/strips substrates into $\mathrm{HCl}$ solution (37\%).

11) Add a little $\mathrm{Zn}$ and wait 10 min until the uncovered ITO is completely etched away.

12) Remove ITO substrates from the $\mathrm{HCl}$ solution, rinse in flowing distilled water.

13) Blow dry with Argon.

14) Peel off the black tapes, and check the conductivity of the patterned ITO.

15) Repeat the ITO cleaning procedures.

16) Place in a UV-Ozone cleaning system (UVOCS Inc.) for $1 \mathrm{~min}$.

17) Move into argon-filled glovebox, ready for the thin-film deposition. 


\subsection{OLED Fabrication}

All the layers of the OLEDs were deposited in a thermal vacuum evaporation chamber installed in an argon-filled glovebox. The deposition procedure was as follows:

1) Quartz crucibles containing the small molecule source materials were loaded in heater coils.

2) The ITO glass substrate was loaded into the chamber.

3) The chamber was pumped down by a turbo pumping system for $0.5 \sim 1 \mathrm{hr}$, until a vacuum of $10^{-6}$ mbar was achieved.

4) The thickness monitor (model TM-100, MAXTEK Inc.) was turned on. The parameters of material density and acoustic impedance were set to the proper values.

5) The HP6260B DC power supply was switched on. For each organic material, the current supply was adjusted to a proper value and the material was preheated for $2 \sim 3 \mathrm{~min}$. Then the shutter was opened for the thermal-evaporation deposition.

6) The heater was turned off, slightly before reaching the target thickness. When the target thickness was reached, the shutter was closed.

7) The thickness monitor and then the turbo pump were turned off. The chamber was refilled and cooled down for $\sim 10 \mathrm{~min}$.

8) The chamber was opened and the next source materials were loaded. Steps $3 \sim 7$ were repeated until all the organic materials were deposited layer by layer.

9) After opening the chamber, the cathode-deposition mask was placed on the organiccoated substrate. Then, the substrate was reloaded into the chamber and the crucibles were replaced by $\mathrm{Al}$-attached heating coils.

10) The same thermal evaporation deposition procedure was repeated for $\mathrm{Al}$ as the cathode.

11) The completed OLED was then encapsulated with corning glass substrates.

The heating current was $20 \mathrm{~A}$ for $\mathrm{CuPc}, 12 \sim 13 \mathrm{~A}$ for $\mathrm{NPD}, 15 \mathrm{~A}$ for $\mathrm{Alq}_{3}, 23 \mathrm{~A}$ for $\mathrm{CsF}$, and $33 \mathrm{~A}$ for $\mathrm{Al}$ deposition. The deposition rate for all layers should be below $2 \AA / \mathrm{sec}$ to ensure good film quality. The multilayer-structure of $\mathrm{Alq}_{3}$ OLED is shown in Fig.2.1. 


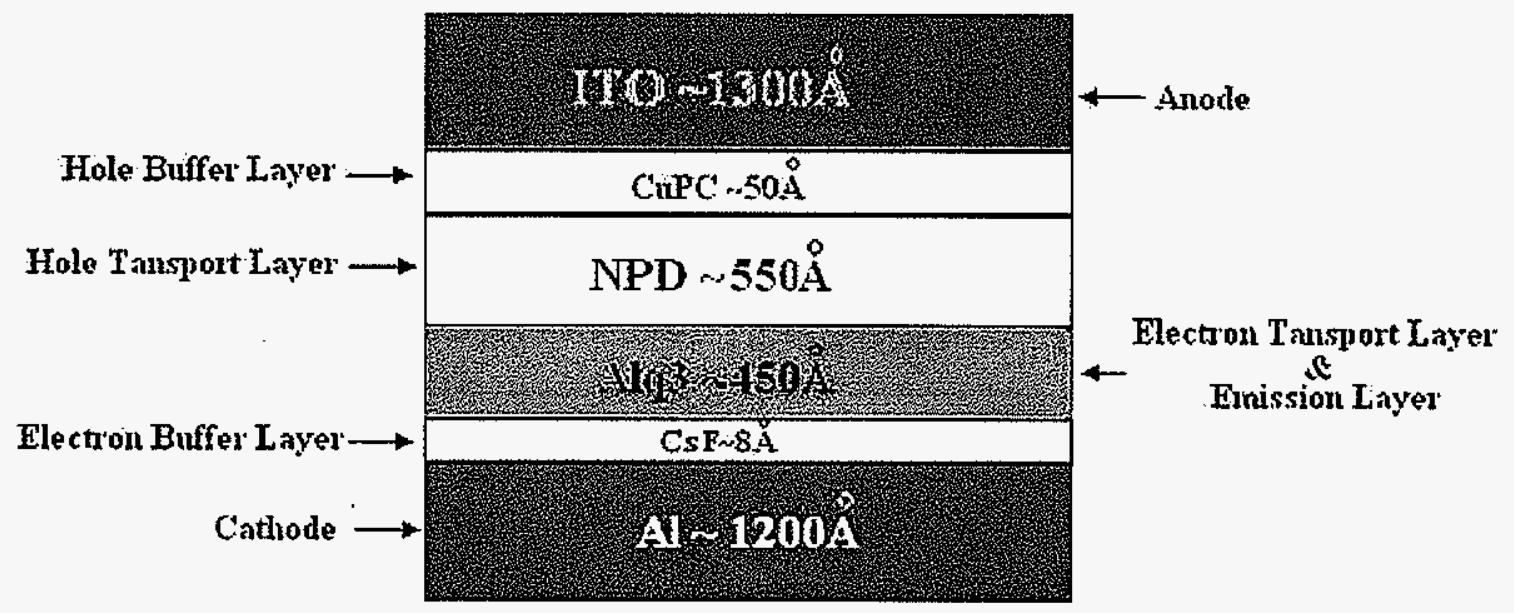

Fig.2.1: Multilayer structure of $\mathrm{Alq}_{3}$ green OLED

Fig.2.2 shows an Alq ${ }_{3}$ green OLED driven by a voltage pulse train with pulse height $\sim 20$ $\mathrm{V}$, pulse width $100 \mu$ s and duty cycle $3 \%$.

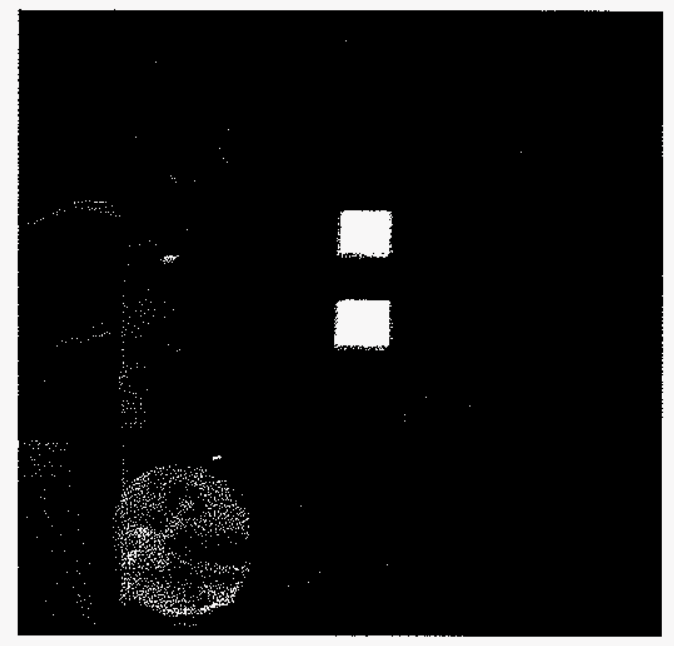

Fig.2.2: Lit pixels $\left(2 \times 2 \mathrm{~mm}^{2}\right)$ of an $\mathrm{Alq}_{3}$ green OLED 


\subsection{Sensor Fabrication}

\subsubsection{Reagents}

PtOEP was obtained form H.W. Sands (Jupiter, FL), and PS from Aldrich (Milwaukee, WI). Toluene was purchased from Fisher Scientific (Pittsburgh, PA). Non-stabilized LOx from pediococcus species and Lactate $97 \%$ for enzymatic assay were purchased from Sigma (St. Louis, MO). Stabilized LOx from Aerococcus viridans was obtained from Applied Enzyme Technology Inc. (Pontypool, UK). Buffer solution (pH 7.4) was prepared by dissolving $8 \mathrm{mM}$ sodium phosphate, $2 \mathrm{mM}$ potassium phosphate, $0.14 \mathrm{M}$ sodium chloride and $0.01 \mathrm{M}$ potassium chloride (Pierce, Illinois) in $500 \mathrm{ml}$ deionized water. All LOx and lactate solutions were prepared in buffer ( $\mathrm{pH}$ 7.4). MTEOS $99 \%$ was obtained from Aldrich (Milwaukee, WI). TEOS was purchased from Fluka.

\subsubsection{Film/solution sensing component}

$2 \mathrm{mg}$ PtOEP and $80 \mathrm{mg}$ PS were added to $1 \mathrm{ml}$ toluene and ultrasonicated for $1 \mathrm{hr}$ until a clear solution was obtained. Then, $10 \mu \mathrm{l}$ of the solution were drop-cast onto corning glass slides. After drying in air for $3 \sim 4 \mathrm{hr}$, uniform films with a diameter of $\sim 5 \mathrm{~mm}$ were obtained. $100 \mu \mathrm{l}$ non-stabilized LOx solution was added to a $200-\mu \mathrm{l}$ cell to which the $5-\mathrm{mm}$ PtOEP sensing film was glued (by Epoxy) as the bottom of the cell. The cell was closed (by a corning cover glass) immediately after the addition of $100-\mu$ lactate solution to the LOx solution. The first PL lifetime data was taken $12 \mathrm{sec}$ after the addition of the analyte. The following data were taken at time intervals of $20 \mathrm{sec}$. We assume that the cell is well sealed and there is minimal oxygen exchange between the cell and the environment during the lactate oxidation. The measurements were taken at $37^{\circ} \mathrm{C}$. The sensor films were rinsed with de-ionized water in between the measurements. The lactate solutions were diluted from a 2 $\mathrm{mM}$ stock solution. 
The use of the stabilized LOx was also studied in this work. The sensing films (diameter $\sim 8 \mathrm{~mm}$ ) were also based on PtOEP:PS. Measurements were performed at $23^{\circ} \mathrm{C}$ or $37^{\circ} \mathrm{C}$. The rest of the experimental procedure was the same as described for non-stabilized Lox.

\subsubsection{Solid-state sensing component}

$2.4 \mathrm{ml}$ MTEOS, $0.8 \mathrm{ml}$ deionized water, $0.7 \mathrm{ml} \mathrm{HCl}(\mathrm{pH}=1)$ and $0.05 \mathrm{ml}$ ethanol were mixed and vortexed for $1 \mathrm{hr}$ until a clear sol-gel solution $(R=7)$ was obtained, then it was kept at room temperature for $24 \mathrm{hr}$ to obtain full condensation. 286 units $/ \mathrm{ml}$ stabilized LOx was prepared by dissolving $20 \mathrm{mg}$ stabilized LOx in $1 \mathrm{ml}$ deionized water. $200 \mu \mathrm{l}$ of the solgel solution was mixed with $200 \mu \mathrm{l}$ of the LOx solution. $10 \mu \mathrm{l}$ of the mixture was spin-coated (P-6000 Spincoater) onto a 5mm-diameter PtOEP:PS film $(2 \mathrm{mg} / \mathrm{ml}$ PtOEP, $80 \mathrm{mg} / \mathrm{ml}$ PS) at spin-rate of 1200 1600 rpm for $1 \mathrm{~min}$. The PtOEP:PS/(LOx+sol-gel) film was dried at $37^{\circ} \mathrm{C}$ for $24 \mathrm{hr}$ before use.

The measurement was taken in a closed cell or an open cell with $100 \mu$ lactate solution at different concentrations. The sensing film was rinsed thoroughly by water in between the measurements.

\subsection{Sensing System}

The $\mathrm{Alq}_{3}$ green OLED is used as the excitation source of the oxygen-sensitive dye PtOEP. The EL emission band of $\mathrm{Alq}_{3}$ peaks at $\sim 530 \mathrm{~nm}$ (see Fig.2.3). PtOEP has an absorption band at $535 \mathrm{~nm}$ and an emission band at $645 \mathrm{~nm}$ (see Fig.2.4) [70]; therefore it can be excited by $\mathrm{Alq}_{3}$ OLEDs.

The change in $I$ and $\tau$ can be detected by the fast PMT; these two modes of detection are the intensity $(I)$ mode and lifetime $(\tau)$ mode, respectively. The $\tau$ mode is preferred because $\tau$ is an intrinsic characteristic; it is independent of external factors that may affect the PL intensity, such as the degradation of light source and the deterioration of sensing dyes [71]. The $\tau$ mode, therefore, eliminates the need for frequent sensor calibration and gives more stable sensor signal than the $I$ mode [26]. 


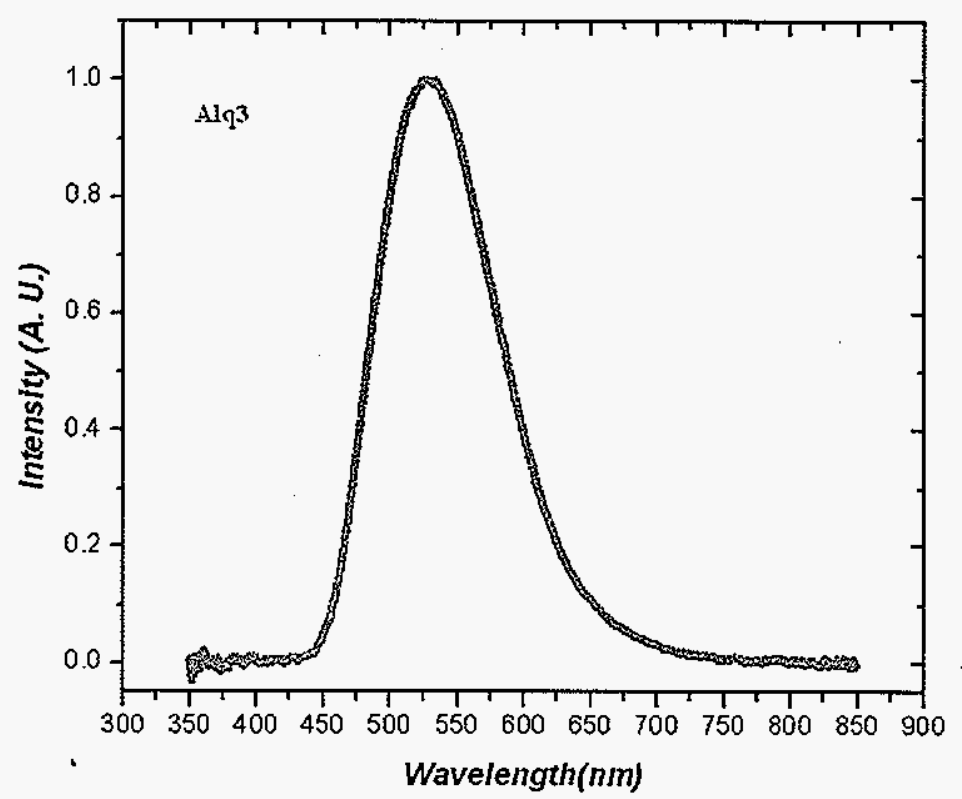

Fig.2.3: Emission band of $\mathrm{Alq}_{3}$.
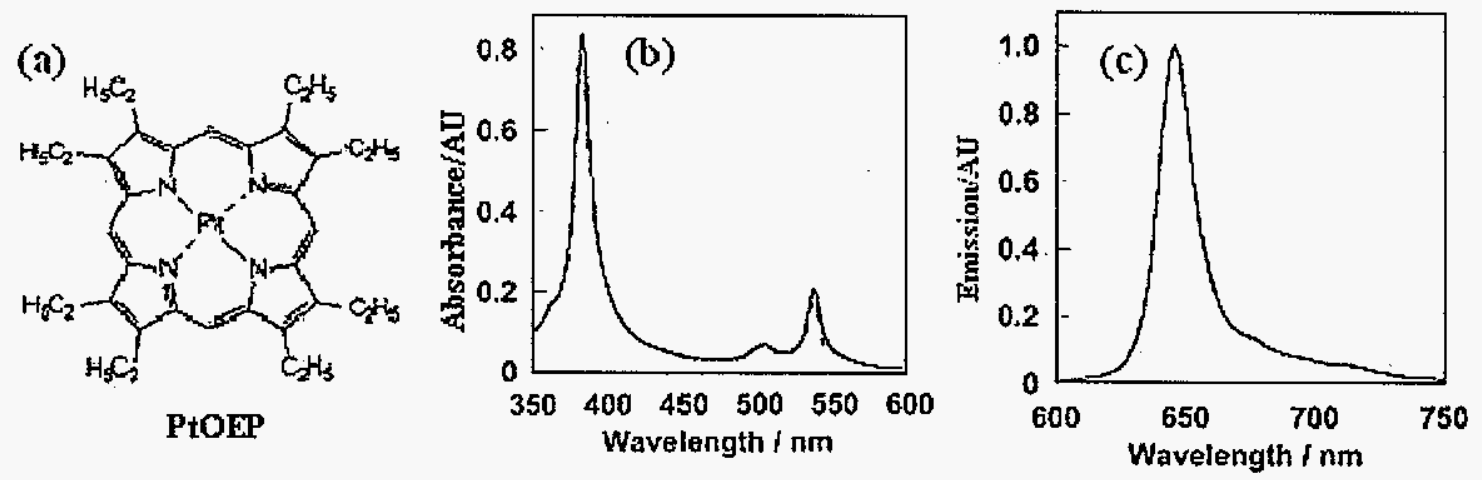

Fig.2.4: a) Molecular Structure; b) Absorption spectrum; c) PL spectrum of PtOEP.

A schematic of the whole sensing system is shown in Fig.2.5. It consists of a Hamamatsu 3456 PMT, an AVTECH AV-1011B pulse-generator, a Tektronix TDS 460 Oscilloscope and a PC running LabVIEW. The pulse generator drives the OLED by a train of voltage pulses, with pulse height $\sim 20 \mathrm{~V}$, pulse width $100 \mu$ s and duty cycle $3 \%$. 


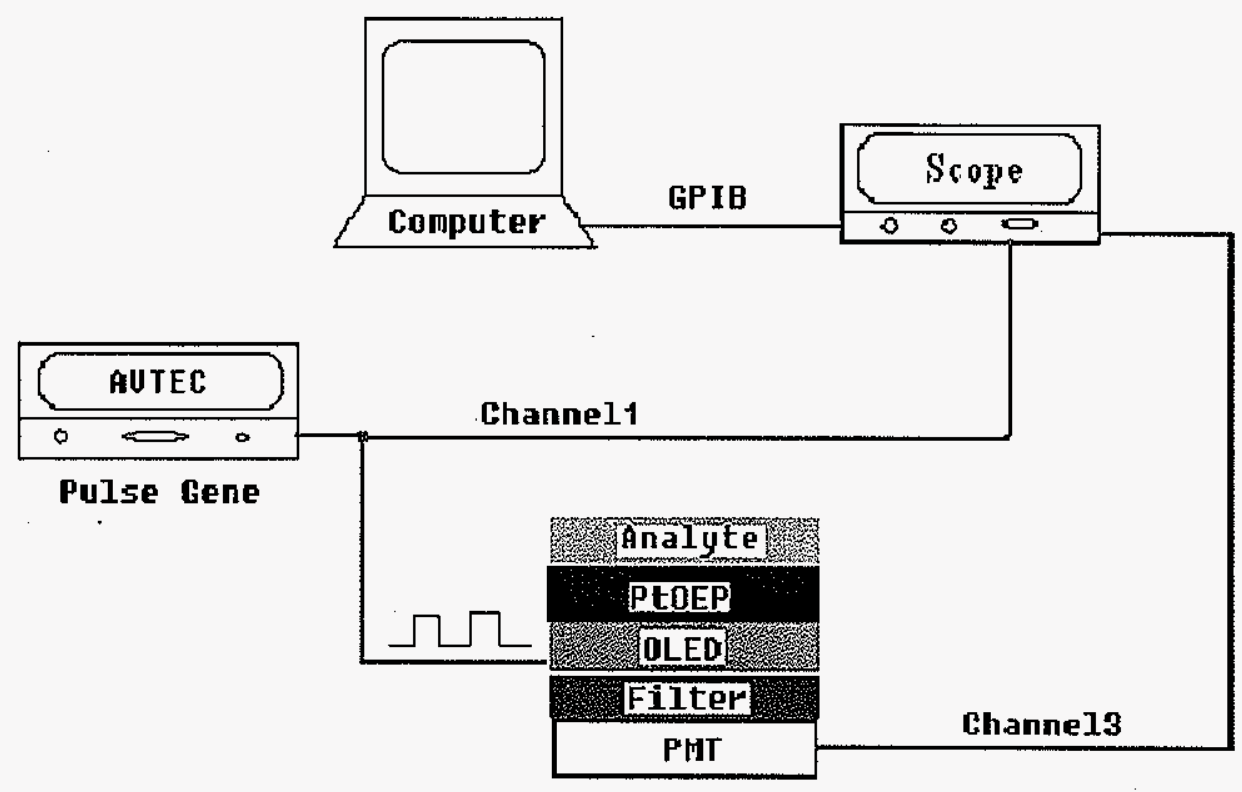

Fig.2.5: Schematic of lactate sensing station.

The OLED was turned on at the pulse rising edge, lasting for $100 \mu \mathrm{s}$, then turned off at the pulse falling edge (less than $10 \mathrm{~ns}$ [72]), which triggered the oscilloscope. Then the $\mu$ sL decay was displayed on the oscilloscope. 


\section{CHAPTER 3. RESULTS AND DISCUSSIONS}

\subsection{Film/Solution Sensing Component}

Fig.3.1 shows a typical sensor response at various lactate concentrations for a PtOEP:PS sensing film and non-stabilized LOx in solution. The LOx concentration was 0.75 units $/ \mathrm{ml}$. One unit will oxidize $1.0 \mu \mathrm{mole} / \mathrm{min}$ of lactate at $\mathrm{pH} 6.5$ at $37^{\circ} \mathrm{C}$. The concentration of lactate is in milimolar (mM). $1 \mathrm{mM}$ equals $1 \mu \mathrm{mole} / \mathrm{ml}$.

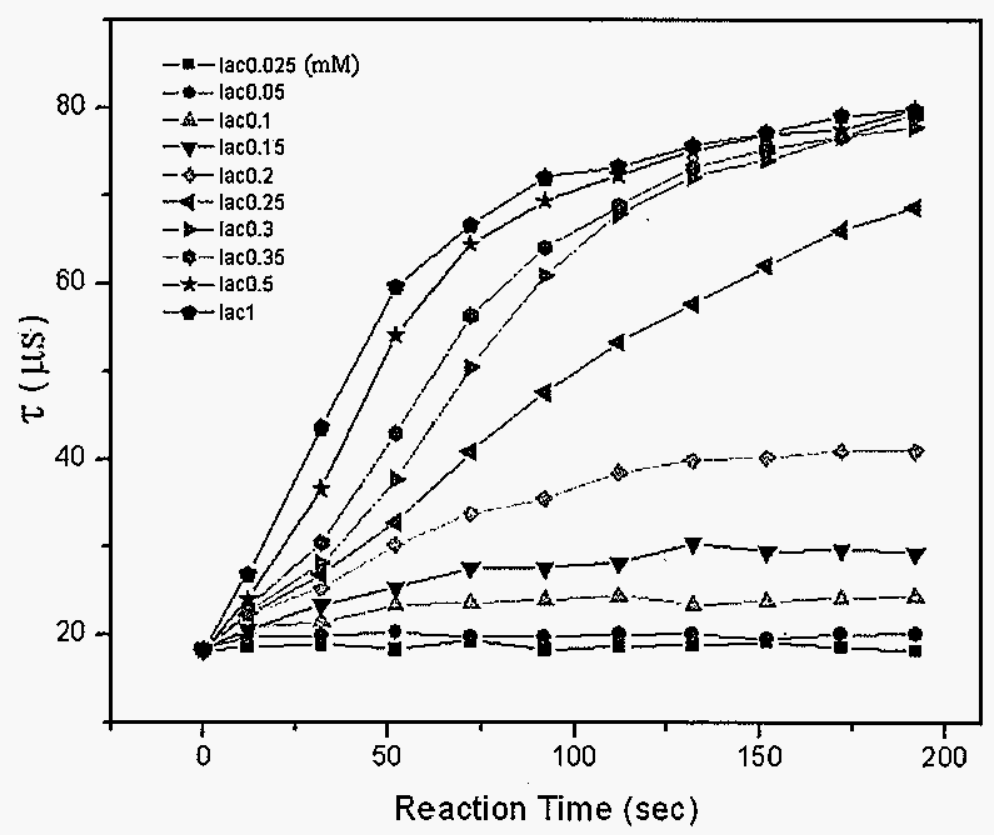

Fig.3.1: Response curves of a PtOEP:PS film ( $2 \mathrm{mg} / \mathrm{ml} \mathrm{PtOEP,} 80 \mathrm{mg} / \mathrm{ml} \mathrm{PS}$ ) at different lactate concentrations in a closed cell, for $0.75 \mathrm{units} / \mathrm{ml} \mathrm{LOx}$. The lines are a guide to the eye.

As the figure indicates, $\tau$ increased following the addition of lactate solution. All the response curves generally leveled off after a certain reaction time. When using 0.75 units $/ \mathrm{ml}$ LOx the response time (time required to reach $\sim 90 \%$ of the plateau value) exceeded $\sim 2.5 \mathrm{~min}$ for lactate concentrations $>0.2 \mathrm{mM}$. As also seen, for lactate concentrations $>0.3 \mathrm{mM}$, all leveled-off $\tau$ values were comparable. This situation was probably caused by the limited level of dissolved oxygen (DO) in the closed cell and its depletion when the lactate 
concentration was larger than $0.3 \mathrm{mM}$. The different leveled-off $\tau$ values at lower lactate concentrations $(<0.3 \mathrm{mM})$ were due to the presence of sufficient DO to react with lactate.

Calibration curves of $\tau$ vs lactate concentration, generated from the data shown in Fig. 3.1 at $12 \mathrm{sec}, 32 \mathrm{sec}$, and $52 \mathrm{sec}$ after the initiation of the oxidation reaction, are shown in Fig.3.2. These calibration curves are linearly fitted. The slope represents the sensitivity at a certain time.

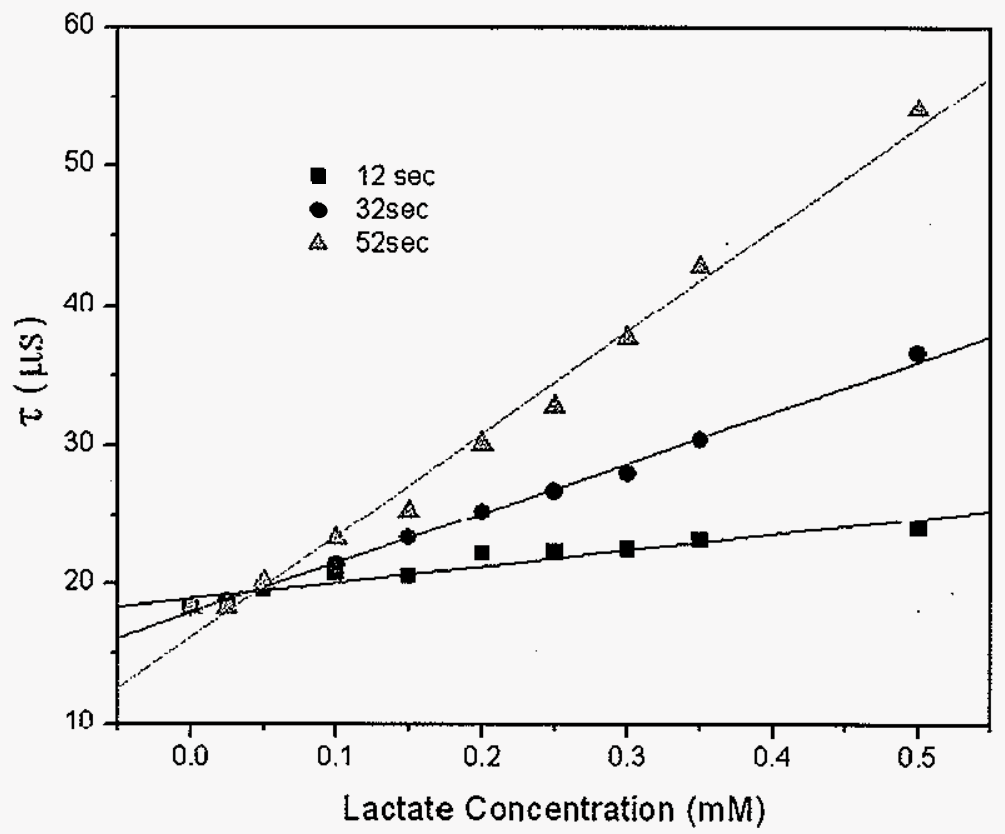

Fig.3.2: Calibration curves for lactate detection using the PtOEP:PS film after $12 \mathrm{sec}, 32 \mathrm{sec}$ and $52 \mathrm{sec}$ of the initiation of the oxidation reaction, for $0.75 \mathrm{units} / \mathrm{ml} \mathrm{LOx}$. The lines are the best linear fits.

It can be seen that the sensitivity increases as the reaction time increases, during these early stages of the reaction. The reaction completed in $\sim 150 \mathrm{sec}$ (see Fig.3.1).

The effect of the enzyme concentration is shown in Fig. 3.3. As seen, increasing LOx concentration accelerates the oxidation reaction. Fig. 3.4 shows calibration curves after $32 \mathrm{sec}$ of the initiation of the oxidation reaction for increasing LOx concentrations. 


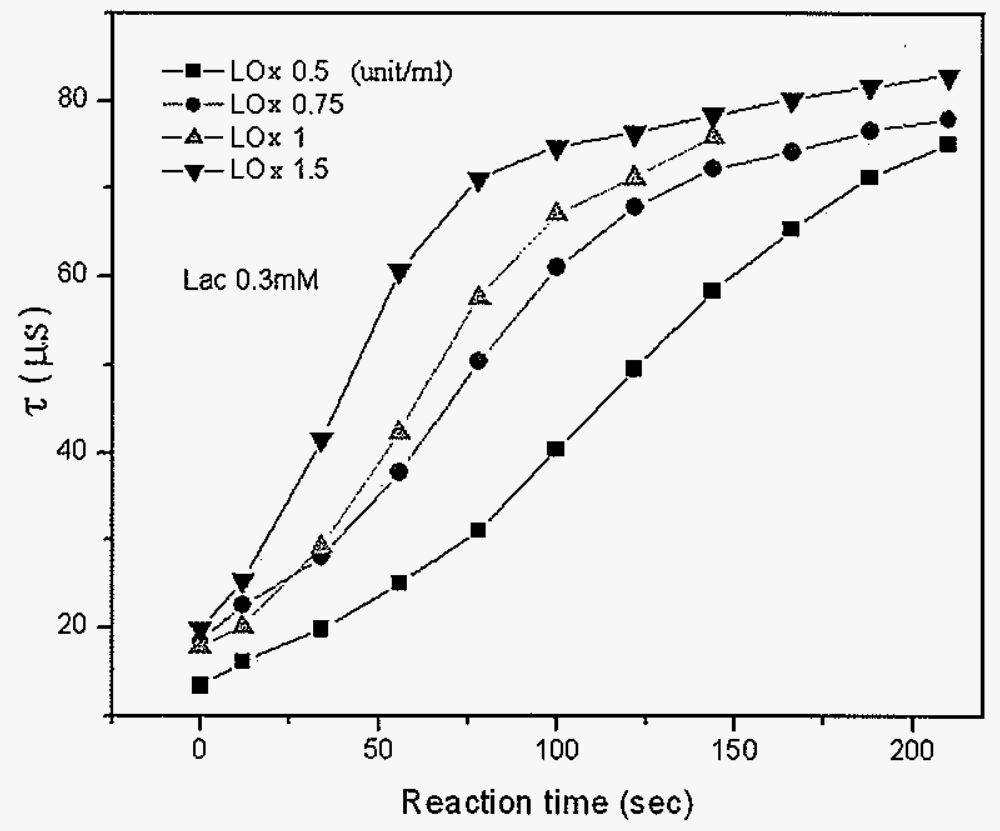

Fig.3.3: Response curves of the PtOEP:PS film, for $0.3 \mathrm{mM}$ lactate and various LOx concentrations. The lines are a guide to the eye.

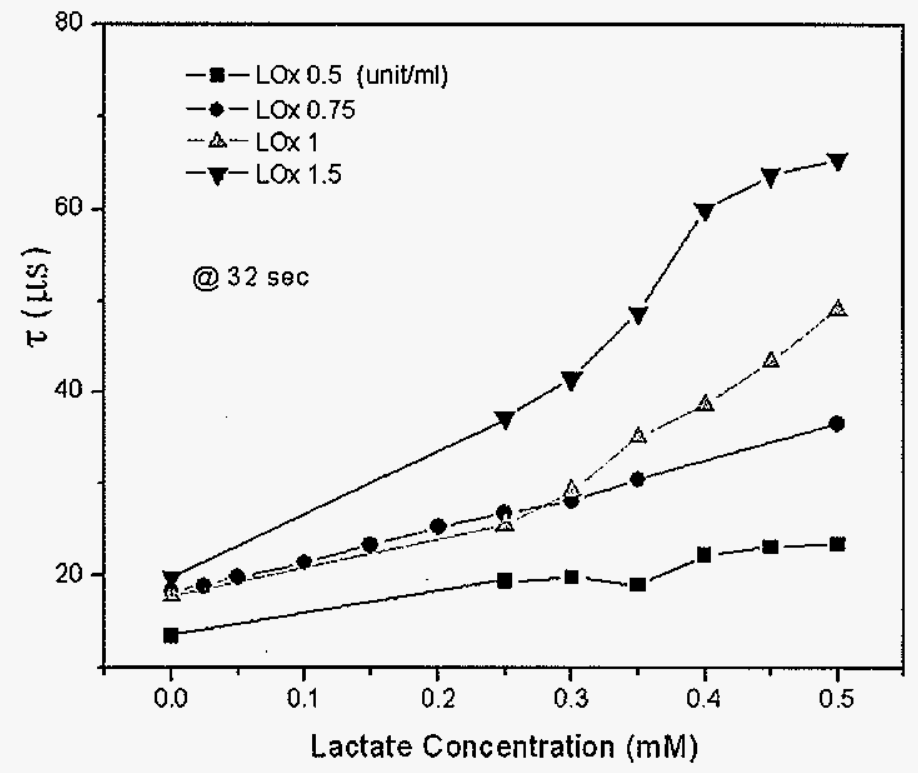

Fig.3.4: Calibration curves of the PtOEP:PS film at various LOx concentrations at 32 sec. The lines are a guide to the eye. 
As Fig.3.4 indicates, the sensor detection sensitivity increases. This is possibly due to increased consumption of DO at $32 \mathrm{sec}$, as the reaction speeds up.

The lactate sensor described above needs to be improved in several aspects. 1) The calibration curve should ideally be obtained from the plateau $\tau$ values in order to make it reproducible and more reliable. 2) The response time should be further reduced. 3) The dynamic range should be increased. The use of the stabilized LOx resulted in improved sensor performance. The results are shown as following.

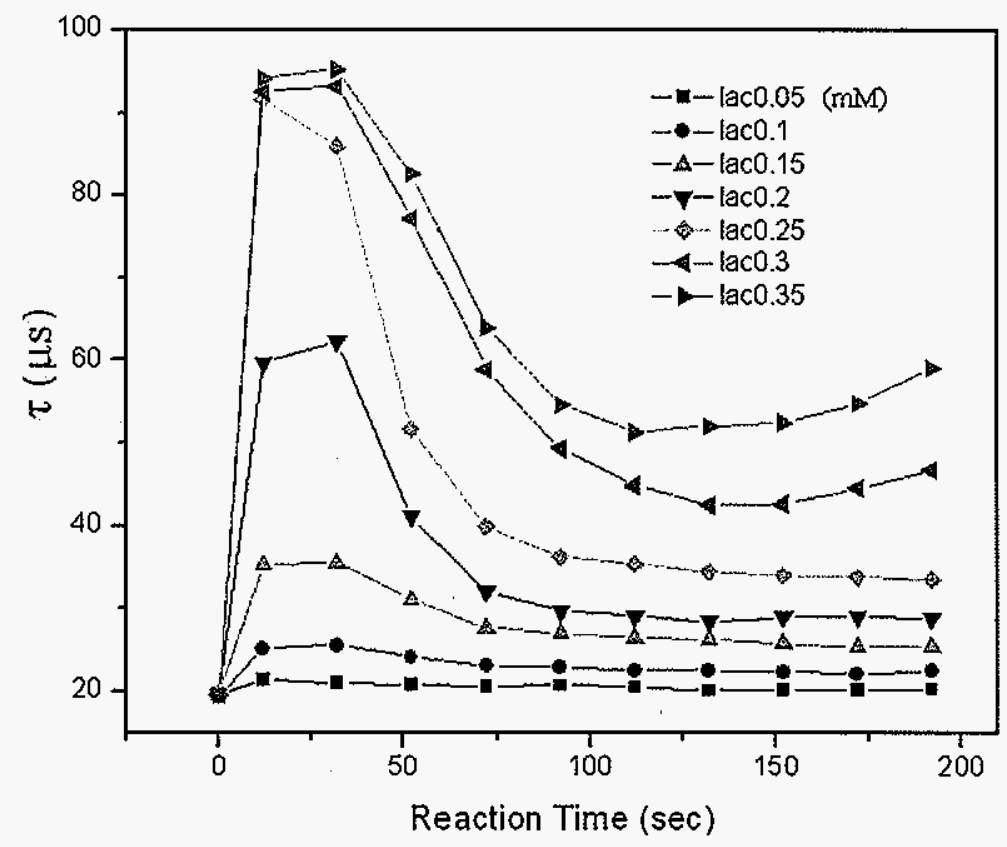

Fig.3.5: Response curves of a PtOEP:PS sensing film (1mg/ml PtOEP, $50 \mathrm{mg} / \mathrm{ml} \mathrm{PS})$ with stabilized LOx in an open cell, at $37^{\circ} \mathrm{C}$. The stabilized Lox concentration was 10 units $/ \mathrm{ml}$. The lines are a guide to the eye.

Fig.3.5 shows response curves for a PtOEP:PS sensing film in an open cell, using stabilized LOx. The stabilized Lox concentration was 10 units $/ \mathrm{ml}$. After the addition of lactate solution, the reaction completed within $\sim 12 \mathrm{sec}$. That is, the response time for this lactate sensor is $\sim 12 \mathrm{sec}$. However, $\tau$ values decreased quickly after $\sim 32 \mathrm{sec}$. This decrease is due to the dissolution of ambient oxygen following the consumption of lactate. On the time scale shown, the DO concentration increases ( $\tau$ generally decreases) probably until a steady- 
state DO concentration is achieved. To avoid the situation described above, the measurements were performed in a closed reaction cell to minimize the exchange of oxygen with ambient. The results are shown in Fig.3.6.

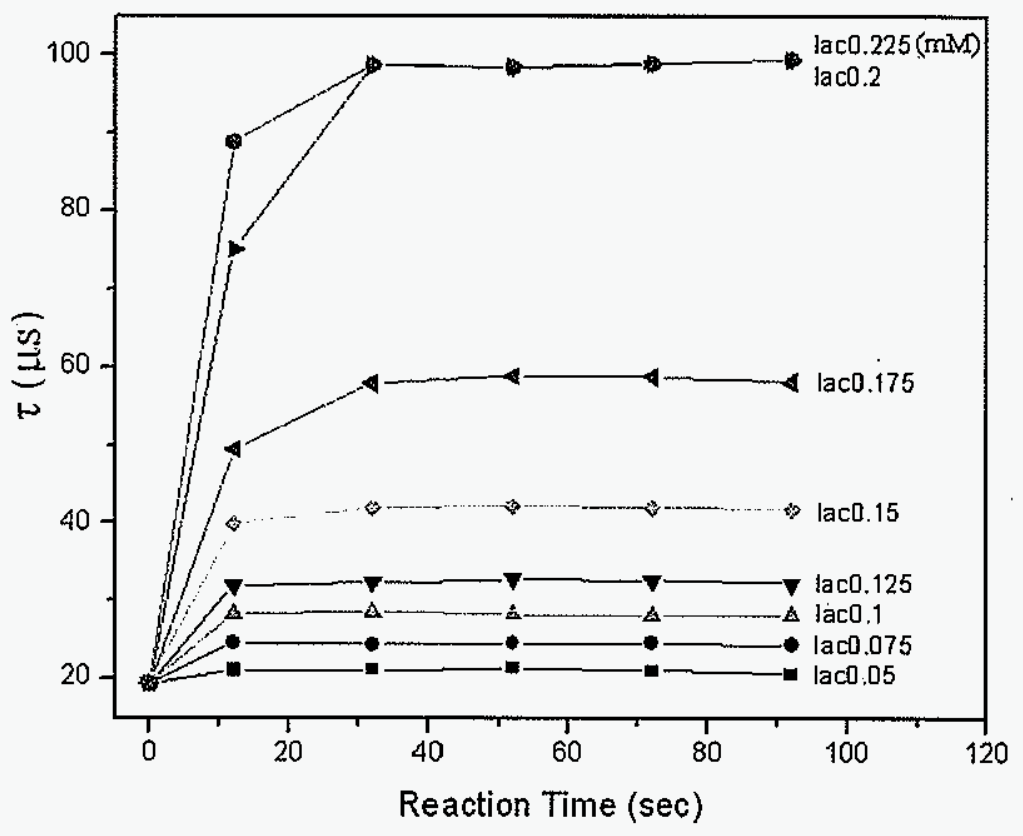

Fig.3.6: Response curves of a PtOEP:PS sensing film $(0.8 \mathrm{mg} / \mathrm{ml}$ PtOEP, $40 \mathrm{mg} / \mathrm{ml}$ PS) in a closed cell, at $37{ }^{\circ} \mathrm{C}$. The stabilized LOx concentration was 7.5 units/ml. The lines are a guide to the eye.

As seen in Fig.3.6, the value of $\tau$ remains constant after reaching the level-off value at each lactate concentration. The response time is around $32 \mathrm{sec}$, which is significantly shorter than the response time of $\sim 150 \mathrm{sec}$ observed for the non-stabilized LOx (see Fig.3.1). Calibration curves, generated form the data shown in Fig. 3.6 after $52 \mathrm{sec}$ of the initiation of the oxidation reaction, are shown in Fig.3.7. The $\tau_{0} / \tau$ vs lactate concentration curve at $52 \mathrm{sec}$ was plotted in Fig.3.8. $\tau_{0}$ here is the maximal decay lifetime of $\sim 99 \mu \mathrm{s}$, when lactate concentration is $0.2 \mathrm{mM}$. 


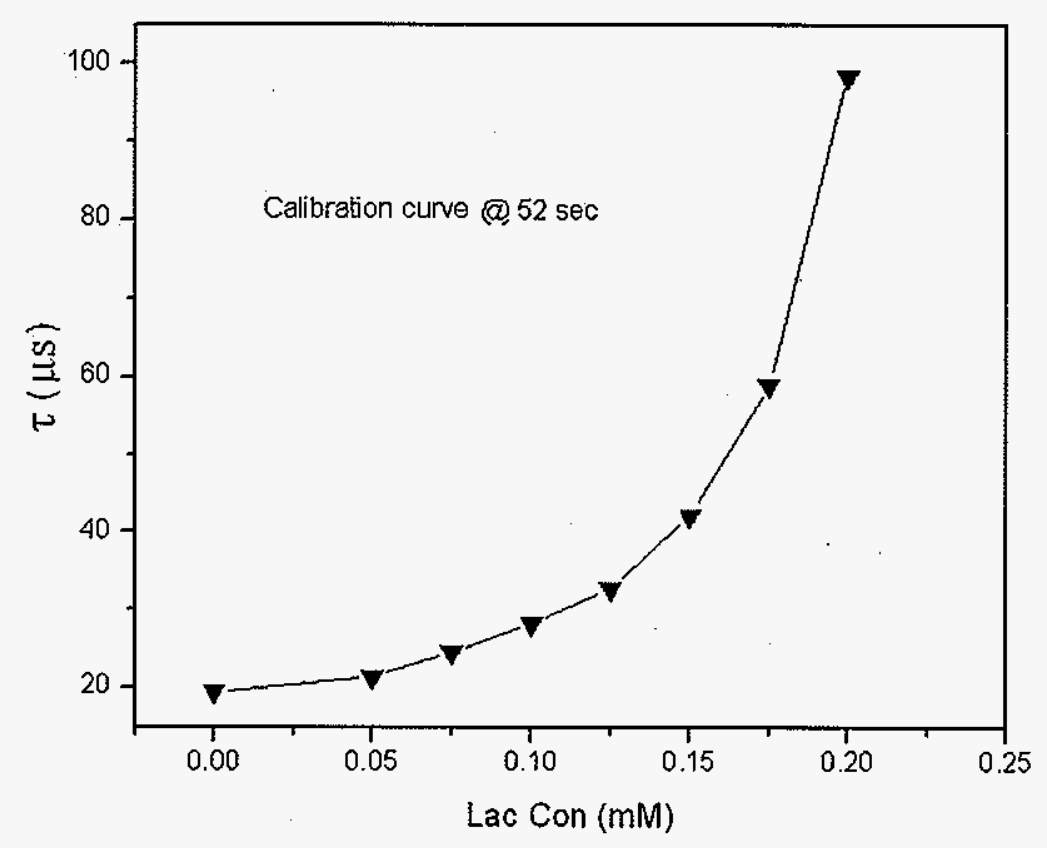

Fig.3.7: Calibration curve of the PtOEP:PS sensing film, for 7.5 units/ml stabilized LOx. The measurement was performed in a closed cell, at $37^{\circ} \mathrm{C}$. The line is a guide to the eye.

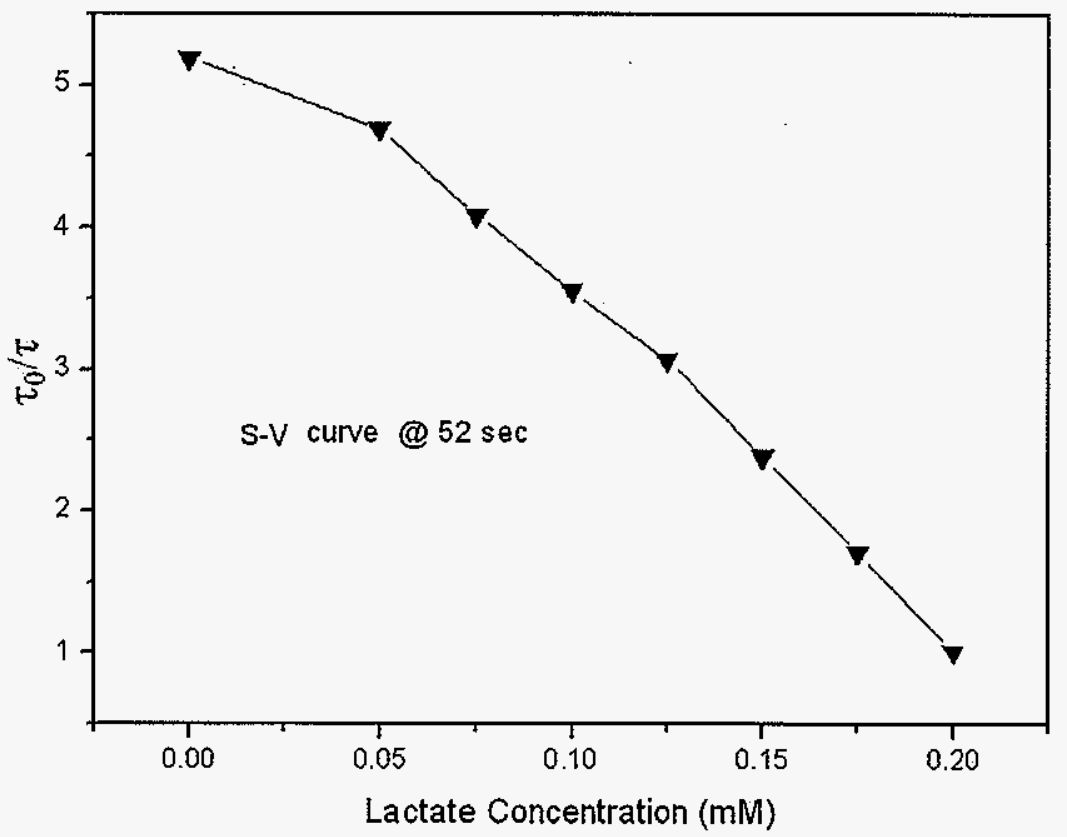

Fig.3.8: S-V curve of the PtOEP:PS sensing film, for 7.5 units $/ \mathrm{ml}$ stabilized LOx. The measurement was performed in a closed cell, at $37^{\circ} \mathrm{C}$. The line is a guide to the eye. 
As seen in Fig.3.7, the calibration curve is not linear; it is different from the reported linear calibration plots for PL-based glucose biosensors [20, 23, 73] and ethanol biosensors [22]. In biosensors based on PL quenching by DO, the sample is often stirred or used in a flow cell, where the DO-saturated analyte solution flows constantly [20, 22, 23, 73]. Therefore, in such a case, the steady state (i.e. a leveled-off sensor response curve) is established by a dynamic equilibrium between the rates of oxygen consumption and supply [22]. However, in this work, the initial DO in the closed cell was $\sim 7 \mathrm{ppm}$, which

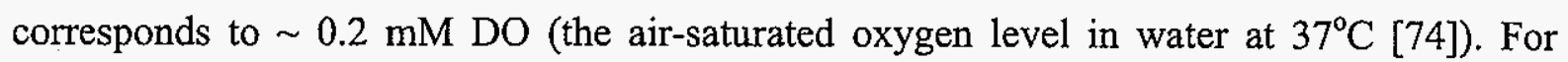
lactate concentrations $<0.2 \mathrm{mM}$, the different leveled-off $\tau$ values (see Fig. 3.6) were due to the presence of sufficient DO for the reaction with lactate. The $\tau$ value was determined by the amount of residual DO after the reaction was completed. But for lactate concentrations $>0.2$ $\mathrm{mM}$, the comparable leveled-off $\tau$ values were a result of the depletion of DO in the closed cell. The dynamic range of this sensor is limited to $0.05 \sim 0.2 \mathrm{mM}$.

As indicated in Fig.3.8, the $\tau_{d} / \tau$ vs lactate concentration curve curve fits the linear S-V relation (see Equ.2), with the $\left[\mathrm{O}_{2}\right]$ term replaced by lactate concentration; therefore the $\mathrm{K}_{\mathrm{SV}}$ is negative.

The measurement was also taken at $23^{\circ} \mathrm{C}$. The response curves are shown in Fig.3.9. A comparison of calibration curves of the sensing film at $23{ }^{\circ} \mathrm{C}$ and $37 .{ }^{\circ} \mathrm{C}$ is shown in Fig.3.10. 


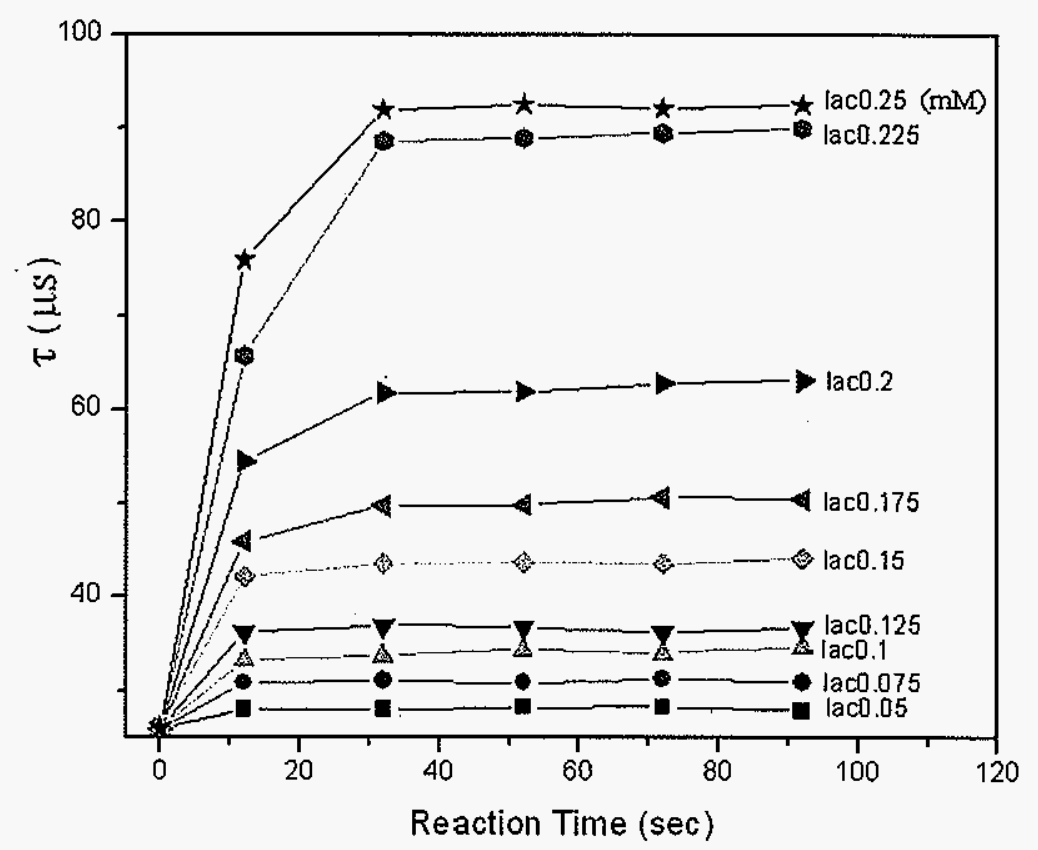

Fig.3.9: Response curves of the PtOEP sensing film in a closed cell. LOx concentration was 7.5 units $/ \mathrm{ml}$. The measurement was performed at $23^{\circ} \mathrm{C}$. The lines are a guide to the eye.

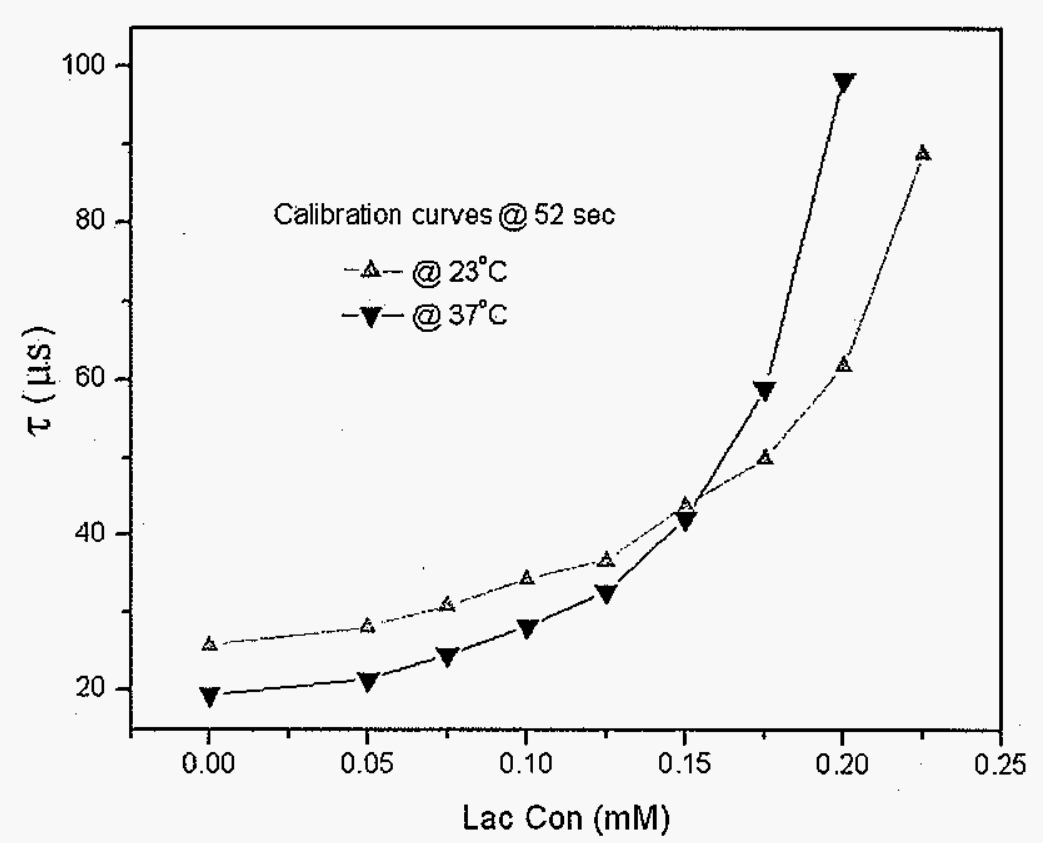

Fig.3.10: Comparison of calibration curves of the sensing film at $23{ }^{\circ} \mathrm{C}$ and $37{ }^{\circ} \mathrm{C}$. LOx concentration was $7.5 \mathrm{unit} / \mathrm{ml}$. The lines are a guide to the eye. 
The dynamic ranges at $23^{\circ} \mathrm{C}$ and $37^{\circ} \mathrm{C}$ are comparable (see Fig.3.10), but the measured $\tau$ at $\sim 0.25 \mathrm{mM}$ lactate was shorter at $23^{\circ} \mathrm{C}$, indicating a somewhat higher DO level. This is probably a result of more air-saturated DO at $23{ }^{\circ} \mathrm{C}$ than at $37{ }^{\circ} \mathrm{C}$ [74]. Additional measurements at different temperatures are needed to establish the temperature effect.

To evaluate the optimal enzyme concentration, experiments were performed using 7.5, 10,15 , and 20 units $/ \mathrm{mL}$ stabilized LOx. No measurable effect on the detection sensitivity was observed.

The response time of the OLED-based sensor with LOx in solution is relatively short $(\sim 32 \mathrm{sec})$ in comparison to that of other PL based biosensors with LOx embedded in a film, where a response time of $3 \mathrm{~min}$ was reported [9]. The slower response time is a result of a slower diffusion of the analyte into the LOx-containing film. The dynamic range of our sensor, however, is limited due to the fast depletion of DO in the closed cell, without continued supply. Future work with the OLED-based lactate sensor where LOx is in solution should include the use of oxygen-saturated solutions in a closed cell, or possibly the use of oxygen flowing above the analyte in an open cell configuration. This is expected to increase the dynamic range, as a larger DO concentration will be available for the oxidation reaction.

\subsection{Solid-State Sensing Component}

The advantage of a film-based sensor is its robustness and ease of use. We therefore tested PtOEP:PS / (LOx doped MTEOS sol-gel) sensing films.

As seen in Fig.3.11, the dynamic range is larger, extending to $\sim 0.5 \mathrm{mM}$ (relative to $\sim 0.2$ $\mathrm{mM}$ obtained for LOx in solution). However, the $400 \mathrm{sec}$ response time is longer compared with the $\sim 32 \mathrm{sec}$ observed when LOx was in solution (see Fig.3.6). The slower response is expected due to the slower diffusion of lactate into the sol-gel film. 


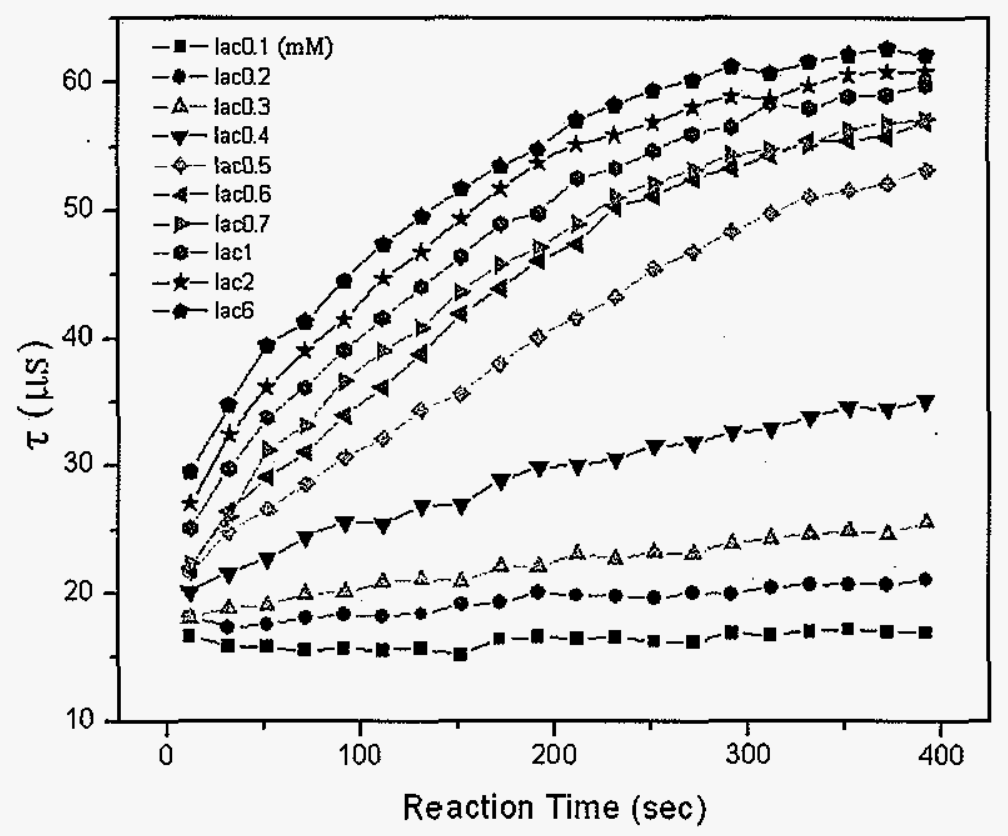

Fig.3.11: Response curves of PtOEP:PS/(LOx+sol-gel $R=7)$ film. The measurement was performed in a closed cell at $37^{\circ} \mathrm{C}$. Stabilized LOx concentration was 286 units/ml before immobilization. The lines are a guide to the eye.

The main issue with the above sensor is irreproducibility, possibly due to inhomogeneous LOx distribution within the film, and enzyme leaching. Leaching was suspected due to a significant decrease in the sensor sensitivity. A capping sol-gel layer was added to the sensing film, either by spin-coating or drop-casting, in order to prevent the leaching problem. We found that films with a thin capping layer (prepared by spin-coating) were superior, in terms of a quicker response and higher sensitivity, to those prepared by drop-casting a thicker capping layer. However, the enzyme leaching still existed by adding a capping layer.

TEOS is a better sol-gel precursor than MTEOS in terms of retaining the enzyme [41, 75]. But the MTEOS-based sol-gel can form a more rigid film above the PtOEP:PS film than the TEOS-based sol-gel does.

We mixed MTEOS and TEOS (molar ratio of 4:1) as the sol-gel precursor both to mitigate the enzyme leaching [46] and to get a rigid enough sensing film. The results are shown in Fig.3.12. 


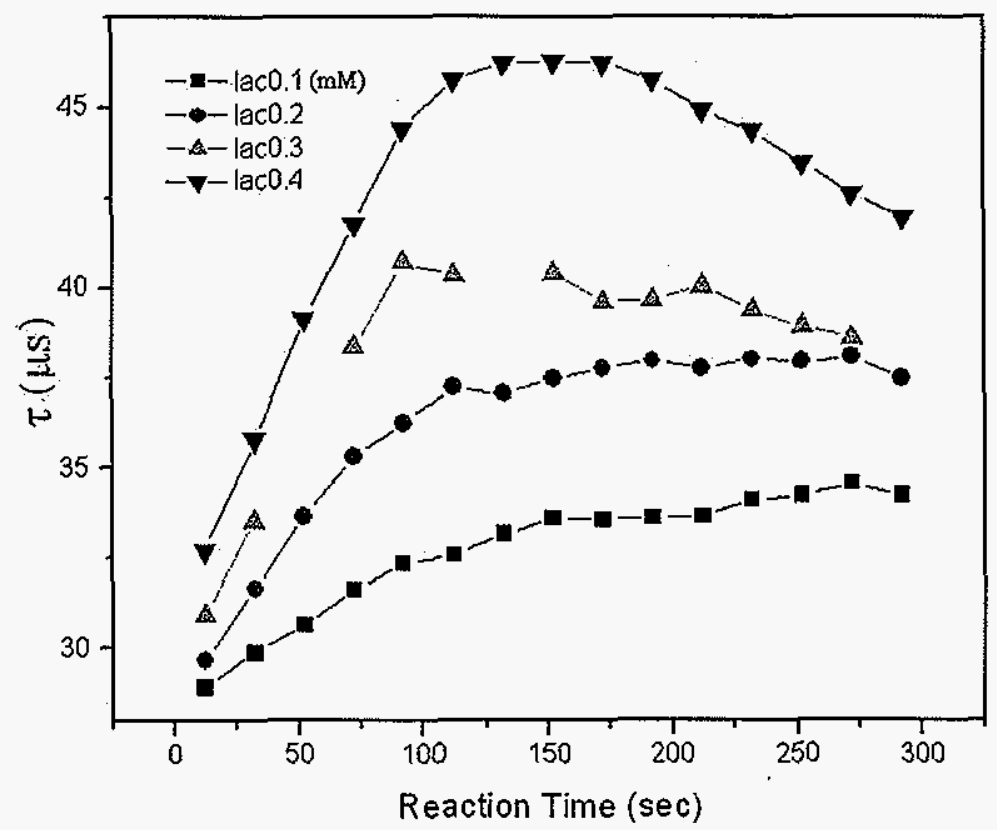

Fig.3.12: Response curves of PtOEP:PS/(LOx+solgel) films. 143 units/ml stabilized LOx solution was mixed with MTEOS:TEOS-based sol-gel (vol/vol 1:1). $25 \mu$ l of the mixture was spin-coated (2800 rpm for $1 \mathrm{~min}$ ) onto each 8-mm-diameter PtOEP:PS film and then dried at $4^{\circ} \mathrm{C}$ overnight. No sol-gel capping layer was applied. The measurements were taken in air at $37^{\circ} \mathrm{C}$. The lines are a guide to the eye.

In the experiment above, each film was used once for a given lactate concentration. The response curves reached a maximal $\tau$ value, which then decreased, indicating an increase in the "diffused-back" DO originating from the ambient. Additional work is needed to reduce the enzyme leaching and enhance the sensor dynamic range.

The normal lactate level in human blood is within the range of $0.5 \sim 2.2 \mathrm{mM}$ [5]. The dynamic range of our sensor, $0.05 \sim 0.2 \mathrm{mM}$ when LOx is in solution or $0.1 \sim 0.5 \mathrm{mM}$ when LOx is immobilized in a sol-gel matrix, is below the lactate range of clinical interest. But samples can be monitored following dilution. 


\section{CHAPTER 4. MULTIANALYTE SENSING ARRAY}

As mentioned, the goal in developing the lactate sensor is to use it as part of a multianalyte sensor array excited by OLED pixels. The sensor array, under development, will be used to test analytes such as oxygen, glucose, lactate, ethanol, and cholesterol; all but oxygen affect the PL of oxygen-sensitive dyes in the presence of specific oxidases [71]. A schematic of the multianalyte array is shown in Fig.4.1.

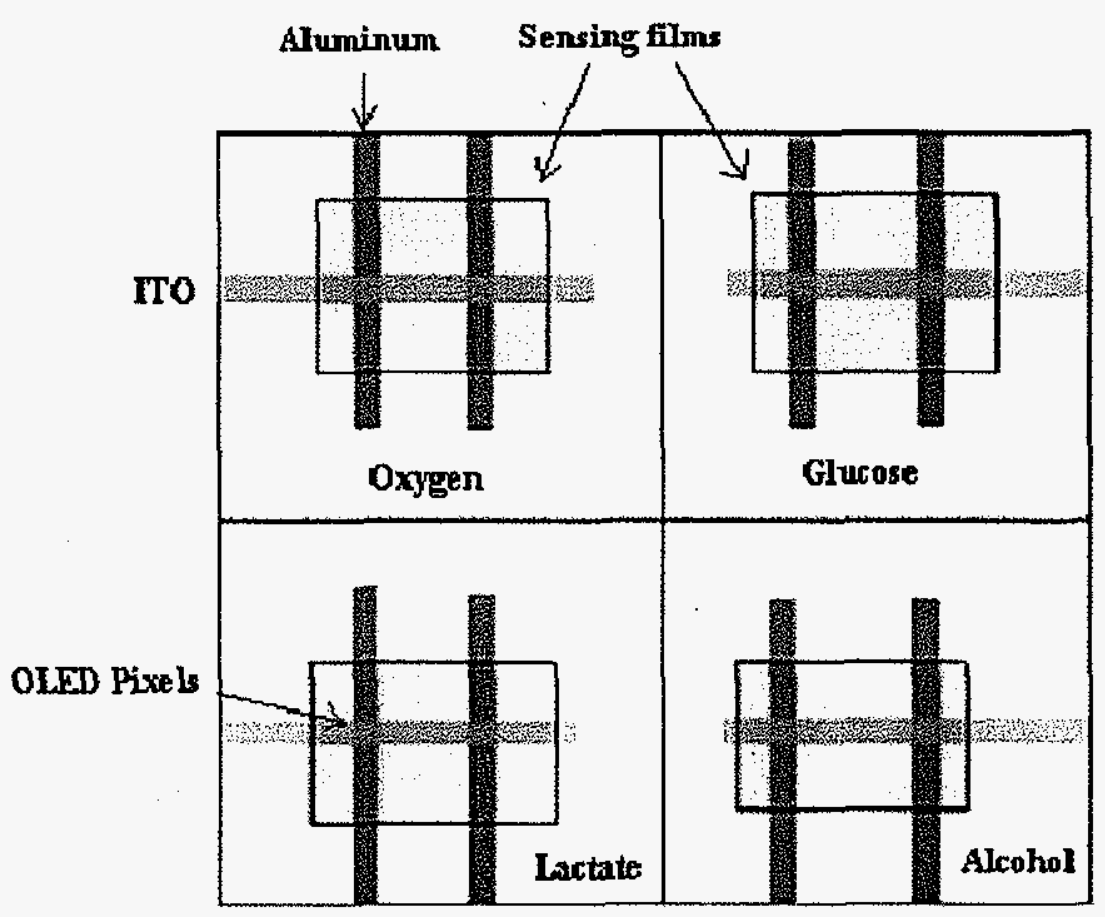

Fig.4.1: Schematic of a multianalyte sensing array. 
A picture of the fabricated sensing array is shown below.

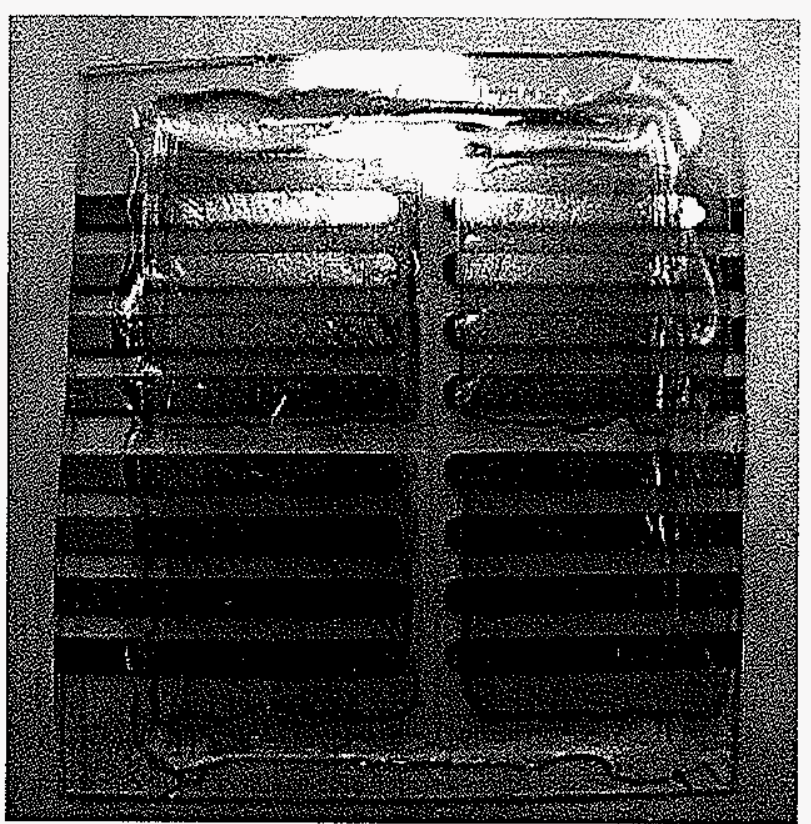

Fig.4.2: A multianalyte sensor array. The pink films are PtOEP:PS films. Specific enzymes are added to the films used for detection of analytes other than DO. 


\section{CHAPTER 5. CONCLUSIONS}

A novel structurally integrated lactate-sensing platform was studied in this work. The PtOEP:PS sensing film and the thin-layered OLED light source can be easily integrated onto a glass substrate, generating a compact sensor. The sensor was operated in the back-detection mode, using changes in the PL lifetime to monitor the analyte concentrations. Monitoring the PL lifetime eliminates the need for frequent sensor calibration. The sensor's configuration, size, and ease of fabrication are advantageous in comparison to other optical lactate sensors, which rely on bulky light sources, or on light sources that are not easily integrated with the sensing component. The effects of the sensor fabrication procedures and resulting attributes on the sensor sensitivity, response time, and dynamic range were described. Issues related to the sensor design and operation were discussed. Additionally, the potential use of the lactate sensor in a multianalyte sensing array excited by individually addressable OLED pixels was demonstrated. 


\section{REFERENCES}

[1] V. Vojinovic, L. Bertin, J. M. Cabral, and L. P. Fonseca, Eng. Life Sci., 6, 181, 2006.

[2] C. Lin, S. Chen, G. Kou, Acta Zoologica Taiwanica, 10, 91, 1999.

[3] D. L. Rothman, A. M. Howseman, G. G. Graham, Magn. Reson. Med., 21, 302, 1991.

[4] G. C. MacQuillan, M. S. Seyam, P. Nightingale, Liver Transplantation, 11, 1073, 2005.

[5] http://www.nlm.nih.gov/medlineplus/ency/article/003507.htm\#Normal\%20Values, May 30, 2006, retrieved on June 23, 2006.

[6] A. Avramescu, S. Andreescu, T. Noguer, Anal. Bioanal. Chem., 374, 25, 2002.

[7] J. P. Guyot, M. Calderon and J. Morlon-Guyot, J. Appl. Microbio., 88, 176, 2000.

[8] P. U. Abel, T. Woedtke, B. Schulz, T. Bergann and A. Schwock, J. Mole. Cata. B, 7 93, 1999.

[9] S. G. Ignatov, J. A. Ferguson and D. R. Walt, Biosen. and Bioelec., 16, 109, 2001.

[10] M. F. Choi, Microchim. Acta, 148, 107, 2004.

[11] S. Hikima, T. Kakizaki, M. Taga, K. Hasebe, Anal. And Bioanal. Chem., 345, 607, 1993.

[12] D. A. Baker and D. A. Qough, Anal. Chem., 67, 1536, 1995.

[13] Q. Yang, P. Atanasov and E. Wilkins, Biosen. and Bioelec., 14, 203, 1999.

[14] H. Minagawa, N. Nakayama, T. Matsumoto and N. Ito, Biosen. and Bioelec., 13, 313, 1998.

[15] L. Clark, L. K. Noyes, T. A. Grooms, M. S. Moore, Crit. Care Med., 12, 461, 1984.

[16] J. Perdomo, C. Sundermeier, H. Hinkers, M. Knoll, Biosen. and Bioelec., 14, 27, 1999.

[17] J. Haccoun, B. Piro, L. Tran, L. Dang and M. Pham, Biosen. and Bioelec., 19, 1325, 2004.

[18] D. P. O’Neal, M. A. Meledeo, J. R. Davis, B. L. Ibey, V. A. Gant, M. V. Pishko and G.

L. Coté, IEEE Sensors Journal, 4, 728, 2004.

[19] O. S. Wolfbeis, Anal. Chem., 76, 3269, 2004.

[20] A. Neubauer, D. Pum and U. B. Sleytr, Biosen. and Bioelec., 11, 317, 1996.

[21] R. C. W. Lau, M. Choi and J. Lu, Talanta, 48, 321, 1999.

[22] K. Mitsubayashi, T. Kon and Y. Hashimoto, Biosen. and Bioelec., 19, 193, 2003. 
[23] O. S. Wolfbeis, I. Oehme and I. Klimant, Biosen. and Bioelec., 15, 69, 2000.

[24] D. B. Papkovsky, Sensors and Actuators B, 29, 213, 1995.

[25] Y. Amao, K. Asai and I. Okura, J. Porphyrins Phthalocyanines, 4, 292, 2000.

[26] B. Choudhury, R. Shinar and J. Shinar, J. Appl. Phys., 96, 2949, 2004.

[27] V. Savvate'ev, Z. Chen-Esterlit, J. W. Aylott, B. Choudhury, C.H. Kim, L. Zou, J. H. Fried, R. Shinar, J. Shinar and R. Kopelman, Appl. Phys. Lett., 81, 4652, 2002.

[28] B. Choudhury, R. Shinar and J. Shinar, Proc. of SPIE, 5214, 64, 2004.

[29] A. Mills and A. Lepre, Anal. Chem., 69, 4653, 1997.

[30] P. Hartmann and W. Trettnak, Anal. Chem., 68, 2615, 1996.

[31] G. Gauglitz, Sensors Update, 1, 1, 1996.

[32] P. Hartmann and W. Ziegler, Anal. Chem., 68, 4512, 1996.

[33] R. Shinar, Z. Zhou, B. Choudhury and J. Shinar, Analytica Chimica Acta, in press, 2006.

[34] Z. Zhou, R. Shinar, B. Choudhury, L. B. Tabatabai, C. Liao and J. Shinar, Proc. of the SPIE, 5994, 100, 2005.

[35] A.C. Pierre, Biocata. and Biotrans., 22, 145, 2004.

[36] J. Livage, T. Coradin and C. Roux, J. Phys.: Condens. Matter., 13, R673, 2001.

[37] D. Avnir, S. Braun, O. Lev and M. Ottolenghi, Chem. Mater., 6, 1605, 1994.

[38] U. Narang, P. N. Prasad and F. V. Bright, Anal. Chem., 66, 3139, 1994.

[39] B. Lillis, C. Grogan, H. Berney and W.A. Lane, Sensors and Actuators B, 68, 109, 2000.

[40] J. Lin and C. W. Brown, Trends in Anal. Chem., 16, 200, 1997.

[41] J. Wang, Anal. Chim. Acta., 399, 21, 1999.

[42] C. McDonagh, B. D. MacCraith and A. K. McEvoy, Anal. Chem., 70, 45, 1998.

[43] Q. Chen, G. L. Kenausis and A. Heller, J. Am. Chem. Soc., 120, 4582, 1998.

[44] M. Altstein, G. Segev, N. Aharonson, Orna Ben-Aziz, A. Turniansky and D. Avnir, J. Agric. Food Chem., 46, 3318, 1998.

[45] H. R. Luckarift, J. C. Spain, R. R. Naik and M. O. Stone, Nature Biotech., 22, 211, 2004. 
[46] M. D. Gulcev, G. L.G. Goring, M. Rakic1 and J. D. Brennan, Anal. Chim. Acta, 457, 47, 2002.

[47] J. Heller and A. Heller, J. Am. Chem. Soc., 120, 4586, 1998.

[48] I. Gill and A. Ballesteros, J. Am. Chem. Soc., 120, 8587, 1998.

[49] M. L. Ferrer, F. D. Monte and D. Levy, J. of Sol-Gel Sci. and Tech., 26, 1169, 2003.

[50] J. A. Cox, P. M. Hensley and C. L. Loch, Microchim. Acta, 142, 1, 2003.

[51] M. L. Ferrer, F. D. Monte and D. Levy, Chem. of Mat., 14, 3619, 2002.

[52] C. W. Tang and S. A. VanSlyke, Appl. Phys. Lett., 51, 913, 1987.

[53] R. H. Friend, R. W. Gymer, A. B. Holmes, J. H. Burroughes, R. N. Marks, C. Taliani, D. D. C. Bradley, D. A. Dos Santos, J. L. Bredas, M. Logdlund and W. R. Salaneck, Nature, 397, 121, 1999.

[54] P. E. Burrows, G. Gu, V. Bulovi'c, Z. Shen, S. R. Forrest, and M. E. Thompson, IEEE Transactions on Electron Devices, 44, 1188, 1997.

[55] C. Adachi, R. C. Kwong, P. Djurovich, V. Adamovich, M. A. Baldo, M. E. Thompson and Stephen R. Forrest, Appl. Phys. Lett., 79, 2082, 2001.

[56] S. A. VanSlyke, C. H. Chen and C. W. Tang, Appl. Phys. Lett., 69, 2160, 1996.

[57] J. Shinar, Organic Light-Emitting Devices: A Survey, NY: Springer-Verlag, 2004, ISBN 0387953434.

[58] K. Cheon, PhD Dissertation, Iowa State University, 2003.

[59] M. Baldo, PhD Dissertation, Princiton University, 2001.

[60] B. J. Chen, W. Y. Lai, Z. Q. Gao, C. S. Lee, S. T. Lee and W. A. Gambling, Appl. Phys. Lett., 75, 4010, 1999.

[61] A. J. Pal, R. Osterbacka, K. Kallman and H. Stubb, Appl. Phys. Lett., 71, 228, 1997.

[62] Y. Shirota, Y. Kuwabara, H. lnada, T. Wakimoto, H. Nakada, Y. Yonemoto, S. Kawami and K. Imai, Appl. Phys. Lett., 66, 807, 1994.

[63] K. Sugiyama, H. Ishii, Y. Ouchi and K. Seki, J. Appl. Phys., 87, 295, 2000.

[64] W. Yu , J. Pei, Y. Cao and W. Huang, J. Appl. Phys., 89, 2343, 2001.

[65] C.W.Tang, S. A. VanSlyke and C. H. Chen, J. Appl. Phys., 65, 3610, 1989.

[66] E.W.Forsythe, M. A. Abkowitz, Y. Gao and C. W. Tang, J. Vac. Sci. Tech. A, 18, 1869, 2000. 
[67] H. Ishii, K. Sugiyama, E. Ito, and K. Seki, Adv. Mater., 11, 605, 1999.

[68] R. Shinar, D. Ghosh, B. Choudhury, M. Noack, V. L. Dalal and J. Shinar, J. of NonCrystalline Solids, in press, 2006.

[69] J. Shinar Organic Device Fabrication, unpublished document, Department of Physics, Iowa State University, 1997.

[70] Y. Amao, K. Asai and I. Okura, Analyst, 125, 871, 2000.

[71] R. Shinar, C. Qian, Y. Cai, Z. Zhou, B. Choudhury and Joseph Shinar, Proc. of the SPIE, 6007, 600710, 2005.

[72] User Manual for AVTECH 1011 series, www.avtechpulse.com, 2006.

[73] Z. Rosenzweig and R. Kopelman, Sensors and Actuators B, 35-36, 475, 1996.

[74] http://www.sensorex.com/support/education/DO_education.html, retrieved on June 23, 2006.

[75] A. Chaubey, K. K. Pande and B. D. Malhotra, Anal. Sci., 19, 1477, 2003. 